\title{
GUERRA TOTAL: MÉXICO Y EUROPA, 1914
}

\author{
Alan Knight \\ Oxford University
}

Z $\mathrm{n}$ los últimos años los historiadores de México han gozaCdo y explotado una plétora de aniversarios (centenarios, bicentenarios); aunque 2010 fue el colmo de este ciclo, hay todavía aniversarios por venir (como las dos constituciones, la de Apatzingán 2014 y la de Querétaro en 2017). Mientras que los aniversarios tienen una función historiográfica - provocan debate, reevaluaciones y difusión - pueden también distraernos de nuestra investigación cotidiana, no conmemorativa. Por tanto, me siento un poco culpable invocando otro centenario, el de 1914-2014. En Europa, por supuesto, ya sufrimos de la fiebre centenaria, que ha provocado tanto nuevos estudios como intervenciones políticas mal pensadas. ${ }^{1}$

Fecha de recepción: 25 de julio de 2014

Fecha de aceptación: 15 de octubre de 2014

${ }^{1}$ Por ejemplo, la declaración del controvertido exministro de Educación británico, Michael Gove, de que la izquierda había subestimado y distorsionado el heroico papel del ejército británico durante la primera 
En México, 1914 ha merecido menos atención (que yo sepa), aunque fue el año que vio el triunfo de las revoluciones constitucionalistas y zapatistas, la caída del régimen porfirista/huertista, la extinción del antiguo ejército federal, las convenciones de México y Aguascalientes, y el rompimiento entre Villa y Carranza que dio lugar a la "guerra de los ganadores".

Mientras que estos procesos a veces han sido estudiados comparativamente bajo la rúbrica de las "grandes revoluciones", casi nunca -que yo sepa- han sido vistos en términos de la guerra, específicamente la "guerra total". Pero se puede sostener que una forma de "guerra total" afectó tanto a México como a Europa en 1914 (en adelante), y que esta forma de guerra tuvo características y consecuencias distintas, evidentes en ambos casos. Sin embargo, mientras que la guerra total europea ha sido ampliamente investigada y el centenario actual está aumentando la cantidad, si no la calidad, de esta investigación, la guerra total mexicana ha sido descuidada. Por supuesto, hay numerosos estudios de la Revolución - nacional, regional, y local; política, económica y socialen donde hay referencias a las batallas, las escaramuzas, la represión militar, el reclutamiento y la logística. Pero, como advierten Ariel Rodríguez Kuri y María Eugenia Terrones, los aspectos militares de la Revolución han sido seriamente descuidados (observación confirmada por la investigación reciente). ${ }^{2}$ Es cierto que las historias - con más frecuencia las

guerra mundial, lo que provocó una fuerte respuesta del partido laborista, amén de la de varios historiadores profesionales. Véase Michael Gove, "Why Does the Left Insist on Belittling True British Heroes?", en Daily Mail (2 ene. 2014) y "Labour Condemns Michael Gove"s Comments on First World War", en Observer (4 ene. 2014).

2 Rodríguez Kuri y Terrones López, “Militarización, guerra y 
memorias - de los generales tienen algo de la perspectiva que John Keegan llama "napierista", es decir, al estilo del general William Napier, historiador de la guerra peninsular, que trata las batallas como juegos de ajedrez, vistos desde arriba, con bastante retórica exaltada, pero que hace caso omiso de los aspectos más amplios del conflicto: la tecnología y psicología de la guerra, la experiencia de los soldados rasos y los civiles, y la dimensión económica y logística (las comunicaciones, el transporte, el suministro y el servicio médico - si existió-). ${ }^{3}$ También se enfoca en los detalles bélicos, sin pensar en los resultados cumulativos de la guerra, en términos políticos, económicos y sociales. Es una crítica válida de la antigua historia militar de la Revolución, que queda atrapada en un surco "napierista" - una "historia de bronce" militar, se puede decir - mientras que la "nueva historia militar", que trata de trascender las batallas y los generales y ampliar ese enfoque, ha tenido muy poco impacto. Se pueden sugerir varias razones de este descuido: la reacción revisionista contra la "historia de bronce", la presunción de que las memorias de muchos generales, como el compendioso estudio de Obregón, Ocho mil kilómetros en campaña, son fuentes oficiales y por tanto no muy fiables, ${ }^{4} \mathrm{y}$ la tendencia, muy lógica, de los

geopolítica”, pp. 177-178. Joseph y Buchenau, Mexico's Once and Future Revolution, aunque nos da un buen análisis sociopolítico de la Revolución, dice muy poco sobre la historia militar (la batalla de Torreón, el encuentro clave en el conflicto entre Huerta y los constitucionalistas, no merece ni una mención). Una notable excepción, es decir, un estudio que trata el tema militar con tino y perspicacia es el de PORTILLA, Una sociedad en armas.

${ }^{3}$ Keegan, The Face of Battle, pp. 35-40.

${ }^{4}$ Obregón, Ocho mil kilómetros en campaña. Claro, hay que leer esta y otras fuentes similares con cierto escepticismo - a veces "contra el 
historiadores jóvenes, de buscar terrenos nuevos en la historia posterior a 1940, en especial en el campo cultural (de ahí el enfoque en 1968, la contracultura, la protesta popular, etc.). Hoy en día hay más interés en la guerra sucia de los setenta que en la antigua guerra revolucionaria de los diez. Por tanto, la historia militar de la Revolución queda a la zaga. ${ }^{5}$

Entonces, mi idea en este artículo es - como dice Edward Thompson - "rescatar del enorme aire superior [condescendencia] de la posteridad" la historia militar de la Revolución, ${ }^{6}$ al mismo tiempo que se sugieren algunas comparaciones - que yo sepa jamás estudiadas - entre México y la Europa de 1914.

grano", al estilo de Ranajit Guha y la "escuela subalterna" -, pero todavía son útiles, especialmente cuando son historias casi contemporáneas, como en el caso de Obregón (y escritas, también en el caso de Obregón, por un individuo muy inteligente, dotado de una memoria "eidética"). Además, recordemos que hace décadas hubo críticas de la obra por su subjetivismo y su egocentrismo. Véase Barragán Rodríguez, Historia del ejército, t. 2, pp. 328-330, cuya defensa del papel del general Francisco Murguía, supuestamente denigrado por Obregón, tiene un eco desde abajo en la entrevista con el veterano villista Arturo Ruiz Quintana, quien afirma que Murguía era "el único general enemigo a quien Villa consideraba un rival digno de él”: Berumen Campos, "Entrevista con un villista sobreviviente", p. 643.

${ }^{5}$ Vale la pena mencionar otro factor: el acceso al archivo de la Defensa Nacional. Cuando hace muchos años pedí acceso al archivo, me lo negaron y no insistí en mi petición, como debí haberlo hecho. Mi impresión es que recientemente el acceso se ha vuelto más abierto. Vale aclarar entonces que este ensayo no incluye datos tomados directamente del archivo de la Sedena.

6 Thompson, The Making of the English Working Class, p. 13. El "rescate” que propuso Thompson incluyó a los tejedores empobrecidos, los artesanos "utópicos" y los "seguidores engañados de [la profeta] Joanna Southcott"; en mi caso, los rescatados son los oficiales, los guerrilleros, los “juanes", y, se puede decir, los "seguidores engañados y coaccionados de Victoriano Huerta". 
En primer lugar, vale aclarar unos puntos conceptuales. Los dos casos, México y Europa, son diferentes en un sentido importante y es claro que uno fue una guerra civil revolucionaria, más o menos limitada al territorio nacional, mientras que el otro fue una guerra internacional, entre las grandes potencias de ese entonces. La guerra de 1914-1918 o 19141919 fue sin lugar a dudas una guerra mundial, ${ }^{7}$ aunque no fue la primera guerra mundial, etiqueta más correcta para la guerra de los Siete Años, 1756-1763, cuando en palabras de Macaulay, "para que [Federico el Grande de Prusia] pudiera robar a su vecina [María Teresa de Austria] a quien había prometido proteger, hombres negros se pelearon en la Costa de Coromandel y hombres rojos se escalparon al borde de los Grandes Lagos de Norteamérica". ${ }^{8}$ Como guerra mundial, la de 1914-1918/1919 afectó a todos los continentes; ${ }^{9}$ y México jugó un papel marginal pero interesante en la contienda, debido al telegrama Zimmermann de 1917 - el esfuerzo

7 Aunque la guerra europea terminó en noviembre de 1918, las medallas militares -como la de mi abuelo paterno, todavía en mi posesión- llevan la inscripción: “The Great War for Civilisation, 1914-1919” (“La Gran Guerra para la Civilización”), siendo 1919 el año en que la mayoría de los soldados salieron del servicio militar.

8 Macaulay, The Life of Frederick the Great, p. 70. Véase también NesTER, The First Global War y PoLLOck, Battle for Empire.

9 Sobre el impacto de la guerra en América Latina, véase Albert, South America and the First World. DeHne, On the Far Western Front, analiza la política británica en la región, mientras que Avner Offer sostiene, con razón, que aun si América Latina apenas participó militarmente en la guerra - como lo haría, en cierta medida, en 1939-1945-, sí hizo una contribución económica importante en pro de los aliados. Offer, The First World War. 
desastroso de Alemania para involucrar a México en una guerra con Estados Unidos-. ${ }^{10}$ El gobierno de Carranza entonces se perfiló, brevemente, en el escenario geopolítico mundial, al menos en el sentido de rechazar la iniciativa alemana. ${ }^{11}$ Aparte de esa decisión México no jugó un papel significativo en la dinámica de la primera guerra mundial (la segunda sería otra cosa); incluso, el abastecimiento petrolero, enfatizado por varios autores, fue mucho menos importante de lo que a veces se supone. ${ }^{12}$ Sin embargo, cambiando la

10 Katz, The Secret War in Mexico, pp. 350-378 es el mejor análisis; Tuchman, The Zimmermann Telegram - aunque sigue siendo citado-, es una obra ya rebasada, cuya interpretación de la revolución mexicana es a veces risible: oponiéndose a Huerta, dice Tuchman, el presidente Wilson "quizá fue cautivado por la nobleza de la larga barba blanca" de Carranza; Huerta no sólo era "un indio de raza pura”, era "un azteca"; Villa, Zapata y Obregón encabezaban "ejércitos privados de gatilleros" ("pistol-bappy private armies") y, Villa, en particular, era "un gallo jactancioso ["a swaggering rooster"] más dispuesto a matar de un tiro a la barriga que a estrechar la mano", al mando de "una chusma que se emborrachaba dos veces por día con tequila y en los intervalos fumaba marihuana”, pp. 39, 42, 45, 66, 88. En contraste, el de BoghardT, The Zimmermann Telegram es un cuidadoso estudio reciente del triángulo angloamericano-alemán, pero dice muy poco sobre México, en parte porque, como opina el autor, p. 6, la maniobra de Zimmermann "no tuvo ningún efecto en México".

${ }^{11}$ La decisión negativa fue - en la frase inglesa hoy en día muy popularun "no-brainer"; es decir, fácil y obvia, ya que la alternativa (positiva) hubiera sido catastrófica para un México que todavía sufría los estragos de una prolongada y costosa guerra civil. En palabras de Obregón, hubiera sido "absurdo" y "estúpido" para México aliarse con Alemania. Eso no quiere decir que la manipulación político diplomática del asunto por parte de Carranza no fuese inteligente: KaTz, The Secret War in Mexico, pp. 364-367.

12 Entre 1916 y 1918 -cuando el auge petrolero en México coincidió con la primera guerra mundial - las exportaciones del petróleo mexicano a Estados Unidos representaron aproximadamente 8\% de la producción estadounidense; además, en 1917, Estados Unidos tenía una reserva 
dirección causal, la guerra fue muy importante para México, también en términos negativos, ya que los temores estadounidenses de la expansión alemana y japonesa tuvieron mayor peso que su preocupación por el trastorno revolucionario al sur de su frontera; por tanto, de 1914 en adelante, la intervención estadounidense en México fue inhibida por las presiones internacionales. ${ }^{13}$ La guerra ofreció a México una ventana de oportunidad en la que el flamante y frágil régimen revolucionario podía afianzarse. La segunda guerra mundial -incluso sus síntomas precursores - conllevó una ventaja parecida en los años 1938-1945, que incluyó, por supuesto, la expropiación petrolera.

Esta historia se conoce bien, aun si las interpretaciones siguen siendo muy diferentes. ${ }^{14}$ Pero no quiero entrar en estos debates; más bien, me enfocaré en la naturaleza y las

de petróleo de más de $40 \%$ de la producción anual nacional. La idea de una inminente crisis de subproducción y escasez fue, en gran parte, una maniobra de las propias compañías petroleras: RiguzzI, ¿Reciprocidad imposible?, pp. 210-213. Hay otro factor: el almirantazgo británico no quería utilizar petróleo mexicano (debido a su contenido químico) y -no obstante el cabildeo de Lord Cowdray- negó facilitar su compra. Brown, Oil and Revolution in Mexico, pp. 146-147.

${ }^{13}$ Como dijo el embajador estadounidense, Henry P. Fletcher, enviado a México en febrero de 1917: "durante la guerra mi tarea fue mantener a México tranquilo y se hizo" " during the war my job was to keep Mexico quiet, and it was done"). Freeman SMith, The United States and Revolutionary Nationalism in Mexico, p. 93.

${ }^{14}$ Sobre las circunstancias internacionales de 1938 en adelante, ScHuler, Mexico between Hitler and Roosevelt, es una buen guía; como también lo es Katz, The Secret War in Mexico, para el periodo 1914-1918 (en mi opinión, mucho de la "guerra secreta" queda como conspiración y conjetura diplomática, que tuvo poco impacto en México). Hart, Revolutionary Mexico, y aún más claramente en Empire and Revolution, enfatiza y, en mi opinión, exagera el impacto, principalmente estadounidense. 
consecuencias de la "guerra total” en México, haciendo hincapié en ciertas comparaciones con la contienda mundial, sin suponer lazos causales directos entre las dos guerras. En primer lugar, hay que definir el concepto de "guerra total". La mejor y breve definición se encuentra en el excelente trabajo de Michael Howard sobre el fenómeno de la guerra en Europa: tal guerra "involucra la movilización total de todos los recursos de la sociedad para una lucha prolongada”. ${ }^{15}$ Esta definición sirve igualmente para guerras internacionales o civiles, por tanto, creo que mi comparación es válida. Y sirve igualmente para América Latina o Europa: Paraguay sufrió una guerra total en su lucha contra la Triple Alianza en 18641870. ${ }^{16}$ La guerra total - una reciente innovación en la larga historia de la guerra - se diferencia de la guerra corta o limitada, que tiene mucho menos impacto en la sociedad beligerante: la guerra de los Siete Años, siendo global, pero no total, provocó aumentos fiscales más una medida de reclutamiento forzoso, pero su impacto en la sociedad británica fue mucho menor que el de las dos guerras globales y totales del siglo xx. ${ }^{17}$ Desde la independencia en 1821, México había

${ }^{15}$ Howard, War in European History, p. 112; véase también p. 93. La definición de Gat, War in Human Civilization, pp. 527-528, también me parece acertada.

16 En palabras de Centeno, Blood and Debt, p. 56: "La Guerra de la Triple Alianza es única en varios aspectos. Debido a su duración, la intensidad emotiva, los desafíos logísticos, y sus consecuencias, no tiene igual en la historia del continente. En América Latina, es la que más se parece al concepto moderno de la guerra total".

17 Durante la guerra de los Siete Años (1756-1763) el gasto militar británico -que incluyó una armada grande y costosa- subió alrededor de $70 \%$ del gasto estatal total, aproximadamente lo mismo que en México en los últimos años de la Revolución, pero, gracias a la robusta economía política británica de ese entonces, este gasto fue financiado "con 
experimentado un sinnúmero de cuartelazos y guerras civiles menores, pero durante casi dos siglos solamente la Revolución y, quizá, en menor medida, la guerra de Reforma y la de la Intervención francesa se pueden considerar guerras totales.

El calificativo "total” exige dos breves aclaraciones más. En primer lugar, en cuanto a su tamaño e impacto es difícil decidir un punto preciso en donde la guerra no total, parcial o limitada, quizá cruza el umbral para convertirse en guerra "total"; Howard, con mucha razón, no ofrece una cifra clara. En efecto, una sociedad en donde un altísimo porcentaje de sus recursos materiales y humanos son dedicados a la guerra sería insostenible. Aun durante la primera guerra mundial hubo renglones de la sociedad europea en donde el impacto de la guerra fue marginal y la vida siguió sin cambios abruptos, mientras que en México el impacto fue muy variable tanto por regiones como por periodos: en 1916, el cónsul estadounidense en Progreso, Yucatán, informó que "aquí está ardiendo la paz [peace is raging], como siempre". ${ }^{18} \mathrm{Sin}$

gran éxito" por aumentos fiscales y préstamos al gobierno: BREwer, The Sinews of Power, pp. 40, 124-125. Para el gasto militar en México véase Wilkie, The Mexican Revolution, pp. 100-102, que da una cifra de $70 \%$ para 1917.

18 "Peace is raging down here, as usual", citado por Joseph, Revolution From Without, p. 93. El estadounidense exageró: Yucatán sí había experimentado violencia, tanto en 1911 como en 1914-1915, cuando los carrancistas aplastaron el movimiento autonomista; $y$, aunque el sistema plantocrático siguió en vigor, la antigua casta divina -la élite porfiriana henequenera- ahora se enfrentó a desafíos tanto internos como de afuera. En las haciendas pulqueras de los llanos de Apam -otra región dominada por grandes terratenientes, "la aristocracia pulquera"- también gozaron de una relativa paz hasta 1914, al menos conforme una versión oral: Olivera (coord.), Mi pueblo durante la Revolución, t. 1, pp. 96, 101, 108. 
embargo, todo México - incluso el lejano sur - fue afectado en cierta medida; y estados/regiones como Chihuahua, La Laguna y Morelos sufrieron cambios drásticos y hasta traumáticos. ${ }^{19} \mathrm{Al}$ mismo tiempo, las guerras totales suelen tener consecuencias mayores y más duraderas - políticas, económicas y sociales-. Entonces, la noción de totalidad es una cuestión de grado y de juicio, muy difícil de medir con precisión, aunque, a mi modo de ver, permanece un concepto útil, incluso esencial, que se asemeja al concepto de la gran revolución o revolución social. ${ }^{20}$

En segundo lugar, me parece que el concepto de guerra total engloba dos aspectos que deben distinguirse y que a veces han sido usados indistintamente. ${ }^{21}$ Tanto en Europa

19 En este contexto vale mencionar el interesante análisis de la economía mexicana durante la Revolución hecho hace unos años por Womack, "The Mexican Economy during the Revolution", pp. 80-123, que, a mi parecer, subestima el impacto económico porque depende de las cifras de exportaciones, que fueron estimuladas por la guerra europea y el primer auge petrolero en México (sobre lo cual, véase KunTz Ficker, "The Export Boom of the Mexican Revolution”, pp. 267-296). Los consecuentes beneficios fueron limitados, en parte por los débiles lazos entre los sectores -quizá los enclaves- exportadores y el resto de la economía, especialmente en el caso del petróleo; y en parte por el gran contraste entre el nivel de vida en esos sectores, por ejemplo, la Franja de Oro petrolífera, y en otras regiones del país, donde sufrían la hiperinflación, el hambre, la destitución, y los estragos de las epidemias, epidemias cuyo vigor también fue elocuente prueba de las pésimas condiciones reinantes. Véase Knight, The Mexican Revolution, t. 2, pp. 406-423. Estos fueron años en que la gente tuvo que vivir del quelite (hierba silvestre) -no sólo en lugares rurales aislados, sino en la propia ciudad de México, Mi pueblo durante la Revolución, t. 1, p. 46.

${ }^{20}$ KNight, "La revolución mexicana: ¿burguesa, nacionalista o simplemente una "gran rebelión”?”, t. 2, pp. 499-565.

${ }^{21}$ Cierta confusión se ve, por ejemplo, en Aron, The Century of Total 
como en América Latina la guerra total involucra dimensiones que se pueden llamar político demográficas y tecnoeconómicas. Estas dimensiones son diferentes. La guerra se volvió total en el sentido político demográfico con las guerras revolucionarias francesas y napoleónicas. En este sentido, la idea de la revolución francesa como el gran estallido que dio lugar al universo histórico moderno tiene algo de verdad. ${ }^{22}$ La revolución francesa originó la idea de la ciudadanía armada (la levée en masse), motivada por sentimientos nacionalistas e ideología política. ${ }^{23} \mathrm{El}$ nacionalismo o, si se prefiere, el patriotismo, no fue una invención de los revolucionarios franceses, pero la unión de nacionalismo, ideología política y movilización militar masiva sí lo fue. ${ }^{24}$ Por tanto, el tamaño de los ejércitos creció: mientras que el rey Federico

War, pp. 19-21, que utilizando un enfoque industrial/ tecnológico, limita la "guerra total" no sólo a la primera guerra mundial, sino al frente occidental, donde fue "una condición accidental y efímera de la guerra".

22 En otros contextos, el uso del modelo francés/revolucionario como passe-partout explicativo no sirve, e incluso es contraproducente -por ejemplo, cuando la revolución mexicana es forzosamente insertada en este modelo: Knight, "La Revolución mexicana de François-Xavier Guerra”, pp. 118-119.

${ }^{23}$ Moran y Waldron (eds.), The People in Arms.

${ }^{24}$ No quiero entrar en el espinoso debate sobre los orígenes y la naturaleza del nacionalismo; vale aclarar que mi opinión -que tiene relevancia para la historia de México y de América Latina- va en contra de los que sostienen que el nacionalismo es esencialmente moderno, producto de la "modernidad", en la forma, otra vez, de la revolución francesa. Para un resumen del debate, véase SмIтH, The Ethnic Origins of Nations, cap. 1. Hay que hacer notar que hubo estados antiguos -como los poleis de la Grecia clásica, incluso Atenas y Esparta- donde se veía también una fusión de ciudadanía, patriotismo y servicio militar. Cohen, The Athenian Nation. Por supuesto, estos fueron estados ciudad, muy diferentes y mucho más pequeños que los estados nación europeos del siglo XIX. 
el Grande, - gran exponente de la tradición militar prusiana- encabezó un ejército de casi 40000 hombres, el ejército que Napoleón reclutó para invadir Rusia en 1812, "el ejército más grande en la historia del mundo", contó con más de $600000 .{ }^{25}$ La combinación del nacionalismo y la ideología política aumentaron las apuestas, conforme los ejércitos revolucionarios (y después napoleónicos) llevaron a lo que Pitt llamó sus "opiniones armadas" por toda Europa, ${ }^{26}$ derrocando a las monarquías, fomentando sentimientos nacionalistas y provocando así un enorme apoyo masivo como oposición. Las campañas más mesuradas y pragmáticas que se vieron durante las repetidas guerras dinásticas del siglo XVIII dieron lugar a las guerras a ultranza, en las que las apuestas políticas eran altas. Características parecidas fueron evidentes durante la guerra civil en México, en especial entre 1913 y 1914, cuando se libró una guerra en que, como sentenció Venustiano

25 Parker, The Military Revolution, p. 147; Esdaile, Napoleon"s Wars, p. 452; Rothenberg, The Napoleonic Wars, p. 164. Sin embargo, de los 611000 hombres movilizados, menos de la tercera parte eran franceses: con Napoleón, la desmesurada ambición y el pródigo desgaste de vidas humanas necesitaron que el ejército francés revolucionario de 1793 -la verdadera levée en masse- se volviera la enorme hueste multiétnica de 1812. La lógica napoleónica, producto de la Revolución que el emperador había secuestrado, dependió del reclutamiento masivo aunado a métodos y ambiciones extremos: como explica EsDaILE, p. 169, "con la llegada de la revolución [francesa], todo se transformó. Pronto, todo fue posible, y esto fomentó una sed de victoria, una agresión y un vigor que difícilmente se vieron en el lado opuesto. Con Napoleón hubo mucho menos preocupación por preservar las vidas de sus soldados que siempre podían ser remplazados por nuevos conscriptos, y poco sentido en adoptar una estrategia cuyo objeto no incluyera la victoria total".

${ }^{26}$ Y más allá de Europa, notablemente en Haití (Saint-Domingue) y, en menor medida, en otras partes de las Américas. La cita de Pitt se ve en Coupland (coord.), The War Speeches of William Pitt the Younger, p. 244. 
Carranza, "revolución que transa es revolución perdida", 27 que involucró altas apuestas políticas, amén de ejércitos de tamaño sin precedente en la historia del país, siendo los ejércitos revolucionarios una suerte de levée en masse motivada por convicciones políticas.

Sin embargo, la guerra total del periodo 1792-1815 no fue un conflicto industrial de alta tecnología; la revolución industrial apenas había comenzado y su impacto inicial tuvo más que ver con la producción textil. Vale mencionar también que estas guerras detuvieron el proceso de industrialización en Europa. El tamaño de los ejércitos aumentó, pero el armamento no había cambiado mucho comparado con la guerra de sucesión española un siglo antes: armas de fuego, tanto fusiles como cañones, cargadas por la boca, que los soldados tenían que disparar de pie; pólvora negra humeante; sables, lanzas y cargas de caballería. Los pertrechos llegaban -si es que lo hacían - en carretas tiradas por caballos o mulas, a veces por sendas lodosas y llenas de surcos y baches. Las batallas de ese entonces tenían que ser cortas - un día, o unos pocos díasporque logísticamente era imposible mantener un numeroso ejército por más tiempo. ${ }^{28}$ La guerra naval - que voy a pasar

27 Richmond, Venustiano Carranza"s Nationalist Struggle, pp. 24-25. ${ }^{28}$ Howard, War in European History, p. 85. Por ejemplo, la batalla de Waterloo (junio de 1815) duró un solo día, igual las de Austerlitz (diciembre de 1805) y Borodino (septiembre de 1812); Wagram (julio de 1809) - "la mayor batalla librada en Europa" hasta ese entonces- duró dos días. Rothenberg, The Napoleonic Wars, pp. 86-91, 130-133, 169170, 207. En comparación la batalla del Somme (1916), en el frente occidental de la primera guerra mundial, duró como mínimo dos meses y medio, o más bien cuatro y medio, hasta el 18 de noviembre. Vale mencionar que, en un solo día (1º de julio de 1916), el ejército británico sufrió 60000 bajas, es decir, cuatro veces las bajas sufridas en Waterloo, 
por alto- involucró barcos de vela hechos de madera, que soltaban de cerca sus andanadas. ${ }^{29}$ Un siglo después -y los indicios tempranos se vieron en la guerra civil estadounidense (1861-1865) y en la guerra franco-prusiana (1870-1871) - la situación fue distinta por dos razones principales. ${ }^{30} \mathrm{La}$ revolución industrial aumentó la producción masiva de armamentos; y éstos, hechos con más precisión, se volvieron más poderosos y certeros. Los rifles reemplazaron a los mosquetes, $\mathrm{y}$ tanto los nuevos fusiles como los cañones ahora se cargaban por la brecha, no por la boca, lo que permitió un fuego más rápido en mayores distancias y disparado, además, por tropas tendidas en el suelo; como necesitaban menos práctica y entrenamiento, hicieron más viable el reclutamiento masivo. Conforme la lógica de la nueva sociedad, la guerra se volvió menos artesanal y más industrial. ${ }^{31} \mathrm{La}$ ametralladora, introducida sin mucho efecto en la guerra civil estadouni-

un siglo antes; como la población del Reino Unido había crecido cuatro veces, la cifra, en términos proporcionales, no fue tan extraordinaria; pero durante los cuatro meses de la batalla, las bajas sumaron a 420000 , es decir, toda una serie de "Waterloos". Keegan, The Face of Battle, cap. 4; Farrar-Hockley, The Somme.

${ }^{29}$ Omito la guerra naval del análisis porque obedece una lógica algo diferente (no hubo ningún levée en masse naval) y tiene poca relevancia en la historia militar de la revolución mexicana. El aspecto más novedoso de la guerra naval de 1914-1918 fue el uso del submarino, que no tuvo ningún papel en México.

30 Sobre estas dos guerras y su relevancia para la práctica bélica, véase Gates, Warfare in the Nineteenth Century, caps. 3 y 4. En torno del debate -todavía inconcluso- sobre la guerra civil estadounidense y si fuera una verdadera guerra total, GAT, War in Human Civilization, pp. 525,527 , opina que "la respuesta obvia es que se quedó a la mitad del proceso" ("it stood half-way in that direction").

31 Howard, War in European History, pp. 102, 120. 
dense, mostró su eficacia mortal en conflictos coloniales y, a partir de 1914, fue utilizada con resultados devastadores en Europa y, como veremos, también en México. ${ }^{32}$ La artillería se volvió más poderosa, más móvil, con mayor alcance. Los cañones cargados de brecha, disparando proyectiles de alto explosivo, transformaron el campo de batalla e hicieron inútiles las tradicionales fortalezas al estilo de Vauban. ${ }^{33}$ Howard observa que "en 1914 un regimiento de cañones de campaña podían lanzar, en un área de unas pocas yardas cuadradas,

32 Gates, Warfare in the Nineteenth Century, p. 141, sobre el impacto de la ametralladora, incluso el "Gatling gun", en la guerra civil estadounidense; una generación después en África, las consecuencias fueron muy diferentes. En la batalla de Omdurman (septiembre de 1896) las fuerzas del Mahdi sufrieron 11000 muertos contra 48 británicos, gracias a las ametralladoras, aunadas al impacto de proyectiles alto explosivos: fue "el más insigne triunfo de las armas científicas contra los bárbaros", en palabras de Winston Churchill (que estaba presente). BecKeTt, The Victorians at War, p. 182. Omdurman confirmó que, en cuanto a la puntería mecanizada, "el gran salto adelante vino con la ametralladora, un producto estadounidense, dirigido hacia el mercado europeo y el campo de acción africano. Sin África la ametralladora hubiera evolucionado mucho más lentamente; sus destinos fueron entretejidos": KiERnan, Colonial Empires and Armies, p. 124. O, como observó el poeta Hilaire Belloc: "whatever happens, we have got/the Maxim gun, and they have not" ("pase lo que pase, nosotros tenemos / la ametralladora, ellos no"). Pero "el que siembra vientos recoge tempestades": sobre el uso devastador de la ametralladora en Europa después de 1914, véase KeEgan, The Face of Battle, pp. 233-234, 247-251.

${ }_{33}$ Sobre Vauban, principal ingeniero militar de Luis XIV, véase PARKer, The Military Revolution, pp. 42-43. En Rusia, antes de la primera guerra mundial, hubo un vivo debate entre los expertos que enfatizaron la gran importancia de las fortalezas tradicionales y los que previeron que estas eran más vulnerables a la nueva artillería pesada, como quedó confirmado con la rápida toma de las fortalezas belgas en Liège y Namur por el ejército alemán en 1914: STONE, The Eastern Front, 1914-191), pp. 30-32, 34, 55 y 175; STEvenson, 1914-1918, pp. 51-52. 
más poder destructivo en una sola hora que todos los cañones disparados por ambos lados durante todas las guerras napoleónicas". ${ }^{34}$ El equivalente naval, producto, en particular, de la rivalidad naval anglo-alemana, fueron el Dreadnought y el Superdreadnought, que podían lanzar proyectiles de hasta $380 \mathrm{~mm}$ (15 pulgadas) a una distancia de 18 kilómetros. ${ }^{35}$ Tanto en tierra como por mar, la muerte fue descargada de lejos, quedando el enemigo remoto y oculto.

Por último, gracias al ferrocarril, los ejércitos podían abastecerse a granel, mientras hubiera recursos suficientes y un sistema logístico adecuado. Por tanto, el frente de batalla se volvió un embudo por el cual se encauzaba la enorme producción de sociedades industriales, al menos mientras las fábricas producían y los ferrocarriles corrían. De ahí el papel clave de los administradores de los ferrocarriles, tanto en Europa como en México. ${ }^{36}$ En México, por supuesto, no

${ }^{34}$ Howard, War in European History, p. 120. Muy eficaz frente a las fortalezas tradicionales, la nueva artillería pesada, no obstante su enorme poder, no podía destruir defensas subterráneas bien preparadas ya que el suelo absorbía el impacto, que se desvanecía en el aire, sin dañar a los defensores bien atrincherados. KeEgan, The Face of Battle, pp. 238-240. 35 Debido a su enorme poder, los cañones y artilleros navales fueron a veces utilizados en batallas terrestres, como el prolongado y mortífero asedio de Verdun en 1916; el ruido de sus disparos podía oírse en el frente del Vosges, a $160 \mathrm{~km}$ de distancia. Horne, The Price of Glory, pp. 51, 84. ${ }^{36}$ Se ha dicho que la primera guerra comenzó debido a la estricta lógica de la movilización masiva y el horario ferrocarrilero: esta interpretación, en ocasiones muy simplificada, se atribuye a TAYLOR, War By Timetable; Stevenson, “The Railway Race Before 1914”, pp. 163-194, ofrece un análisis más reciente. Claro, hay que distinguir entre el impacto de los ferrocarriles en cuanto a la conducta de la guerra, muy importante tanto en México como en Europa, y la cuestión de la causalidad, en la medida en que la guerra europea estalló debido a la imperante e impersonal lógica de la movilización sin que nadie la deseara: una tesis muy parcial 
había una gran industria de armamento; la Revolución dependía de las provisiones de armamento en el país, más importaciones, y la fabricación local, improvisada - en ocasiones exitosa - de bombas y cartuchos. ${ }^{37}$

La tecnología bélica de 1914 también tuvo consecuencias importantes. El poder del armamento había crecido, así como la capacidad para abastecer a los enormes ejércitos por medio de la red ferroviaria; pero, cuando se trataba de tomar y retener el territorio, el papel de la infantería, dotada de fusiles y bayonetas, fue clave. La caballería tradicional tuvo una actuación reducida - en el frente occidental, un papel casi inexistente $-\mathrm{y}$ no hubo ninguna innovación militar que ayudara a las fuerzas ofensivas. La guerra aérea todavía estaba en su primera etapa; los aviones fueron útiles para el reconocimiento, pero tanto en México como en Europa el bombardeo aéreo careció de peso y precisión, y el tanque, usado por primera vez por los británicos en la batalla de Somme, en 1916, fue muy lento, vulnerable y débil para romper el punto muerto en el frente occidental. ${ }^{38}$ En México, como veremos más adelante, la aviación desempeñó un papel menor;

en Europa e irrelevante en el caso de México. En México, el papel clave de los ferrocarriles y, por lo tanto, el papel de los administradores de los trenes, fueron bien reconocidos durante las batallas del Bajío. Véanse Obregón, Ocho mil kilómetros, t. 2, pp. 528-529, 561, 607, 610-612; у GonzÁlez, Contra Villa. p. 63.

37 Por ejemplo, los zapatistas dependían de la fabricación "artesanal" de bombas de dinamita. Olivera (coord.), Mi pueblo durante la Revolución, t. 2, p. 12.

38 Stevenson, 1914-1918, pp. 188-189. Dos años después, los tanques británicos -los alemanes no los tenían- desempeñaron un papel útil, aunque todavía secundario. Stevenson, 1914-1918, p. 444. Veinticinco años después, por supuesto, los tanques de la segunda guerra mundial -más rápidos, fiables y poderosos- serían clave tanto en el blitzkrieg ale- 
además, no había tanques, ni zepelines (dirigibles), ni los temibles lanzallamas. ${ }^{39}$

Entonces, tanto en México como en Europa, el balance de fuerzas, en cuanto a la actual tecnología militar convencional, favoreció la defensa contra la ofensiva, puso en tela de juicio la actuación tradicional de la caballería e hizo clave el papel de la infantería, especialmente la atrincherada, dotada de un fuerte poder de fuego, es decir, ametralladoras. En la nueva ecuación de fuerzas, las fortalezas tradicionales tampoco tuvieron mucho valor, no obstante una observación de Carlos Fuentes. ${ }^{40}$ México, debido a su historia, nunca fue un país de ciudades amuralladas, y las pocas fortalezas que tenía (algunas que todavía hoy se conservan) fueron levantadas cerca de la costa del Golfo (Campeche, San Juan de Ulúa, Perote), lejos de los principales conflictos revolucionarios. ${ }^{41}$ Otro aspecto clave, en ambos casos, el papel de los ferrocarriles y

mán inicial, como en las campañas en los desiertos de África del Norte y las llanuras rusas.

39 Sobre los lanzallamas, y su impacto inicial, véase Horne, The Price of Glory, pp. 91, 92, 95, 96, 98. Vale la pena hacer notar cómo, conforme la constante lucha darwiniana de los beligerantes, los defensores aprendieron métodos para contrarrestar esta nueva arma, inicialmente espantosa. Horne, The Price of Glory, p. 106.

40 "México es un país de muros", Fuentes, A New Time for Mexico, p. 6. ${ }^{41}$ Durante los tres siglos de la colonia no hubo guerras civiles y las rebeliones más serias ocurrieron en la periferia de la Nueva España: Chiapas y Nuevo México. Comparado con la Europa de la guerra de los Treinta Años, México fue un oasis de paz y estabilidad. La amenaza principal vino de afuera, por medio de los "piratas" y buques de guerra extranjeros, especialmente los ingleses; por tanto, las fortalezas fueron construidas en la costa del Caribe. En tiempos de la Revolución, la amenaza de esta índole fue la estadounidense, que resultó en la toma de Veracruz (incluso San Juan de Ulúa) en abril de 1914. 
la capacidad logística, fueron los que mantuvieron al ejército en el campo de batalla bien abastecido. El triunfo de Obregón sobre Villa en 1915 fue resultado de todos estos factores.

Para analizar con más detalle la guerra total en México, propongo tres marcos: 1) Aspectos generales de la guerra, enfatizando la alta mortalidad; 2) La evolución del conflicto revolucionario después de 1910, una historia en parte narrativa, de corto plazo, y 3) Las consecuencias de la guerra total en el largo y mediano término (más o menos, 1917-1940).

La totalidad de la guerra en México es evidente en las cifras demográficas. El mejor análisis reciente es el de Robert $\mathrm{McC}$ aa quien, utilizando una técnica sofisticada de investigación demográfica, sostiene que la Revolución, en su fase armada, 1910-1920, resultó en un déficit demográfico de 2100000 , es decir, la población mexicana en 1921 era de 2100000 menos de lo que hubiera sido sin la Revolución. ${ }^{42}$ Este déficit se compone de nacimientos perdidos que no ocurrieron debido a la Revolución, $25 \%$, y emigración $10 \%$ (175000). Hay que recordar que durante la década de la revolución armada se dio el primer gran flujo de población

${ }^{42}$ McCAA, "The Missing Millions", pp. 367-400. Una de las novedades del análisis de McCaa es que utiliza el censo de 1930, considerado confiable, para corregir los errores del pésimo censo de 1921 en el que todos los expertos coinciden, se subestimó la población y exageró las pérdidas de vidas resultado de la Revolución. McCaa calcula que este error de 1921 fue de 1000000 , produciendo así un déficit demográfico de 2100000 personas. Agradezco al profesor McCaa su comunicación lo cual me permite confirmar que he entendido correctamente su tesis principal. 
hacia Estados Unidos debido a una combinación de factores de empuje: la Revolución y sus consecuencias y un elemento de atracción: la demanda laboral en Estados Unidos, en parte debido a la guerra. ${ }^{43}$ Por tanto, la mortalidad causada por la Revolución representa casi dos tercios del déficit que McCaa calcula en 1400000 , incluyendo a 900000 hombres y 500000 mujeres. Como sugieren estas cifras, McCaa sostiene que la guerra en sí fue muy mortífera; además de la morbilidad causada por la Revolución, hubo epidemias de tifo y, aún peor, gripe española, que afectaron a la población la cual sufría carestía y malnutrición por la guerra, el deterioro económico y el movimiento de gente a lo largo del país. McCaa, con quien coincido, concluye que el costo demográfico de la Revolución fue alto, mayor de lo que han supuesto muchos historiadores, y que la gran mortalidad tuvo que ver no solamente con las enfermedades epidémicas, sino también con la propia violencia, la que en otro trabajo llamé violencia macropolítica. ${ }^{44}$ Esta perspectiva contrasta con la opinión de que - en términos de la mortalidad bélica - la Revolución no fue tan impresionante. Fallaw y Rugeley, dos historiadores sin duda serios y expertos, nos dicen en un libro reciente que la supuesta pérdida de "un millón" es "una cifra que sale de la nada" ("a number from nowbere"), ya que "las mejores estimaciones demográficas atribuyen el millón de mexicanos muertos principalmente a la enfermedad y la migración, no al combate". "Los ejércitos revolucionarios - continúasimplemente no fueron tan letales", por tanto "de ninguna

43 Gamio, Mexican Immigration to the United States, es el estudio clásico de esta primera ola de migración mexicana hacia el norte.

44 Knight, "War, Violence and Homicide in Modern Mexico", pp. 12-148. 
manera comparables a los ejércitos europeos de la Primera Guerra Mundial”; salvo "unos pocos choques épicos” (mencionan los triunfos de Obregón contra Villa “en Guanajuato a principios de 1915”, y, más sorprendentemente, la batalla de Ocotlán de enero de 1924), "las batallas del periodo revolucionario (1910-1938) no fueron de ninguna manera diferentes de sus equivalentes decimonónicos: principalmente actos a larga distancia [long-distance events] con mucho movimiento y poca [guerra de] agotamiento" ${ }^{45}$ La misma opinión se ve en libros de texto recientes. ${ }^{46}$ Claro, si estos historiadores (todos, repito, de renombre) tienen razón, sería ridículo com-

45 Fallaw y Rugeley, "Redrafting History:”, pp. 7-8. Confieso no entender lo que quiere decir encuentros "de larga distancia" " "long-distance”); si quieren decir campañas móviles, hubo muchas en la primera guerra mundial, principalmente en el frente oriental, donde, debido a los grandes espacios y las malas comunicaciones, se libró "una guerra de maniobra": Stone, The Eastern Front, p. 92. En México, las bajas causadas por la Revolución, incluso la lucha militar, fueron enormes. En cuanto al análisis demográfico, la llamada "mejor estimación demográfica" de Fallaw y Rugeley, p. 21, viene de una tesis de maestría escrita en 1966. No citan a McCaa, ni a otros historiadores demógrafos mexicanos como Marta Terán, cuya investigación se resume en "Evolución de la población mexicana, 1895-1970”, pp. 93-102. Fallaw y Rugeley dicen, además, que la cifra de 1000000 [sic] de bajas forma parte de la "historia patria" -como si fuera un mito nacionalista que merece ser destruido junto con los demás mitos. Lo importante, a mi modo de ver, no es lo que sea mítico (o no), sino lo que es correcto.

46 Joseph y Buchenau, Mexico's Once and Future Revolution, pp. 74-75, concluye que "las muertes atribuidas directamente al combate sin duda han sido exageradas" (aunque no dicen por quién o quiénes); aparte de las batallas del Bajío, "los ejércitos revolucionarios no libraron batallas de agotamiento ("battles of attrition"); de hecho, gran parte de la lucha se hizo a larga distancia ("at long range") y con poca precisión ("not very accurately)", ya que hubo falta de ametralladoras y artillería. Otra vez vemos la ambigua frase "a larga distancia” que, presumo, 
parar las grandes batallas de la guerra europea con las insignificantes escaramuzas mexicanas. ${ }^{47}$ Pero yo no concuerdo con estas ideas. Dichos autores han subestimado el grado de lucha bélica en México y los costos consecuentes; me refiero no solamente a los costos demográficos, sino también al impacto en términos económicos, sociales y políticos: en breve, todas las características de una guerra total.

Las cifras globales, conforme el análisis de McCaa, sugieren que México perdió 1400000 habitantes de 15200000 debido a la Revolución (combate+epidemias): es decir, un poco más de $9 \%$. Durante la primera guerra mundial, murieron 9000000 soldados, es decir, $12 \%$ de los 66000000 que pelearon. Esta cifra no incluye la mortalidad civil, aunque en esta guerra - comparada con la segunda - las bajas fueron principalmente entre las tropas. ${ }^{48}$ En el caso de Gran Bretaña - donde nadie duda que la guerra, siendo total y costosa,

no quiere decir el intercambio de fuego por la artillería pesada que, los autores también nos dicen, no existía.

47 En los libros de Fallaw y Rugeley (n. 45) y Joseph y Buchenau (n. 46) hay algo de la antigua presunción que los europeos hacen de las cosas (en este caso, la guerra) con mucho más eficacia y seriedad; la versión mexicana es, quizá afortunadamente, en este caso inferior, algo amateur; la impresión es reforzada por la repetición de estereotipos, como eso de la Revolución, en palabras de Martín Luis Guzmán, "una fiesta de balas": Joseph y Buchenau, Mexico's Once and Future Revolution, p. 75. Mientras que es riesgoso y tal vez hasta presuntuoso tratar de explicar el porqué de las interpretaciones históricas, puede ser relevante que, de los cuatro historiadores citados, tres son, en cuanto a su investigación principal y primaria, expertos en Yucatán, o el sudeste de México donde la Revolución, incluso la revolución armada, tuvo un impacto menor que en el centro y el norte y, en cierto sentido, fue una "revolución de afuera" ("revolution from without"), en palabras del propio Joseph. ${ }^{48}$ Ferguson, The Pity of War, p. 436. 
tuvo un fuerte impacto en la sociedad - más de 700000 combatientes murieron debido a la guerra, es decir, 12\% de las tropas (aproximadamente el promedio global para todos los beligerantes) y $1.6 \%$ de la población total. ${ }^{49}$ Aun si reducimos las pérdidas de mexicanos a 400000 (la diferencia entre los hombres muertos y la mujeres muertas, conforme al análisis de $\mathrm{McCaa}$ ), esta cifra equivale a $2.7 \%$ de la población, es decir, $68 \%$ mayor que la cifra británica, $170 \%$ mayor que el promedio de todos los beligerantes en la primera guerra mundial, y casi igual a la muy alta cifra alemana: 3.0\%. Es difícil evitar concluir que la mortalidad debida a la Revolución fue claramente comparable con la sufrida por las grandes potencias en la primera guerra mundial y que ésta - en términos de impacto demográfico - ofrece una comparación válida con la Revolución.

Esta conclusión se ve reforzada por un análisis de combates particulares y las bajas resultantes. En las dos batallas de Celaya, en abril de 1915, el ejército villista — de aproximadamente 25000 hombres - perdió casi 6000 (24\%). ${ }^{50}$ La batalla

49 Ferguson, The Pity of War, pp. 295, 299. La cifra de 700000 se refiere a Bretaña, es decir, ¿incluye a Irlanda?; el porcentaje se refiere a Bretaña e Irlanda. Ferguson ofrece un porcentaje más alto para Escocia, su país natal, pero supongo que la cifra para Bretaña e Irlanda incluye a Escocia siendo ésta parte integral de la isla de Bretaña. Las bajas sufridas por las tropas imperiales: canadienses, australianos, indios, etc., no están excluidas. Ferro, The Great War 1914-1918, p. 227, ofrece cifras parecidas.

50 UlloA, Historia de la Revolución mexicana, pp. 93, 98, calculó las cifras tomando el promedio de varias estimaciones: entre 20000 y 32000 para el ejército total y entre 3500 y 8000 bajas (las estimaciones de Villa y Obregón respectivamente). En cuanto a las bajas, este cálculo sugiere que hay que deflactar la estimación del ganador-Obregón- por 25\%; claro, la tendencia tanto en México como en otras partes ha sido que los generales suelen exagerar tanto el número del ejército enemigo, como las 
de Trinidad/León fue aún más mortífera y fue seguida por la última gran derrota de los villistas en Aguascalientes en julio, cuando éstos sufrieron bajas de 8500 (5000 dispersos, 2000 tomados prisioneros, y más de 1500 muertos y heridos). ${ }^{51}$ Claro que éstas - las batallas del Bajío - fueron las mayores de todo el periodo de la Revolución. Sin embargo, también debemos incluir las grandes batallas de revolucionarios contra federales en $1914 .^{52}$ En la batalla de Torreón, por ejemplo, los federales sufrieron 5000 bajas: más de 1000 muertos, 2200 heridos, 1500 desertores y 300 prisioneros; las bajas revolucionarias también fueron elevadas: 550 muertos y 1150

bajas del mismo. Por otro lado, la tendencia es subestimar sus propias fuerzas y sus bajas. Puede ser que, sumando las bajas totales, estas tendencias contrarias en cierto sentido se cancelan. Pero esta es simplemente una hipótesis que sería muy difícil probar.

${ }^{51}$ Obregón, Ocho mil kilómetros, t. 2, p. 668. Si utilizamos el deflactor sugerido (nota 50), llegamos a una cifra más modesta de 6000.

${ }^{52}$ Los historiadores mencionados (notas 45 y 46) parecen considerar las batallas del Bajío como grandes batallas convencionales, por lo tanto excepcionales dentro la historia militar de la Revolución; lo hacen, en parte, porque ven al ejército federal como una fuerza de muy poca capacidad: el ejército federal porfiriano, nos dicen Fallaw y Rugeley, "Redrafting History", p. 6, "podrido hasta el meollo, como muchas otras instituciones porfiristas, se colapsó cuando se enfrentó al reto revolucionario poco profesional (relatively amateurish)" de Madero, Orozco, Villa y Zapata. Pero el ejército federal de ninguna manera "se colapsó" en 1911; como dice Portilla, "la mayor parte de las veces que entraron en contacto con los insurrectos hicieron valer la superioridad táctica y de armamiento que poseían" Portilla, Una sociedad en armas, p. 401; por añadidura, mantuvo una resistencia bastante fuerte durante 1913-14, incluso en batallas duras y costosas, como Torreón (abril de 1914). Después, es cierto, vino el "colapso"; éste ocurrió tres años después de la caída de Díaz, tres años en que los federales habían participado en numerosas batallas y campañas, a veces (por ejemplo contra Orozco en 1912) con éxito. 
heridos, un total de $1700 . .^{53}$ Habiendo salido de Torreón, el general federal Velasco se unió con el general Maass en San Pedro, formando un ejército de 10000 hombres que inmediatamente fue derrotado y destrozado por la División del Norte. ${ }^{54}$ En Zacatecas, en junio, la derrota total del ejército federal costó más de 6000 vidas. ${ }^{55}$

La mortalidad de estas batallas se refleja no sólo en las cifras absolutas sino también en las relativas. Aun en encuentros menos conocidos, las bajas fueron relativamente altas. Cuando Cananea fue tomada por los rebeldes sonorenses en abril de 1913, la guarnición federal de 310 soldados perdió 48 (15\%) y 44 resultaron heridos (14\%)..$^{56}$ En 1915 los sitios de El Ébano, Matamoros, Naco y Agua Prieta también produjeron una alta mortalidad, principalmente en el lado de los atacantes (villistas), como mencionaré más adelante. ${ }^{57}$ Aun-

53 González Garza, Ramos Escobar y Pérez Rul, La batalla de Torreón, p. 52.

${ }^{54}$ KNight, Mexican Revolution, t. 2, p. 145.

${ }^{55}$ Knight, Mexican Revolution, t. 2, pp. 166, 168, donde sugerí que la resistencia tenaz de los federales, cuya causa ya estaba perdida, se debió en parte a las tácticas diplomáticas de los delegados huertistas en Niágara. 56 OвREgón, Ocho mil kilómetros, t. 1, p. 210. Otra vez podemos aplicar el deflactor de $25 \%$ para llegar a cifras de 36 y 33 , es decir, $12 \%$ y $11 \%$. ${ }^{57}$ Hay también mucha evidencia "anecdótica" de bajas serias, aun en campañas de poco significado estratégico: por ejemplo, en 1918, Juan Martínez Vidal, de Acatlán, Puebla, siendo un “hombrecito” de 17 años, se enlistó con los zapatistas del general Tacho Plácido, que sumaron 300 hombres; después de un breve encuentro con 200 soldados del gobierno en Tamazulapa (soldados mejor pertrechados), "había muertos y malheridos por todos lados en cuestión de minutos", y los zapatistas, habiendo huido y reconcentrado "en la mesa de un cerro lejano", ya sumaban nada más que 100 (es decir, habían perdido $2 / 3$ de sus fuerzas, muertos, heridos, presos o dispersos). Véase Olivera (coord.), Mi pueblo durante la Revolución, t. 3, pp. 33-35. 
que las cifras absolutas son mucho menores que las del frente occidental en la primera guerra mundial (siendo los ejércitos mexicanos mucho más pequeños), el porcentaje de bajas es comparable. ${ }^{58}$

La discusión de las cifras es complicada porque las bajas incluyen muertos, heridos, prisioneros y dispersos. En ocasiones los heridos mueren (en México como en Europa), pero muchos de los prisioneros también murieron ejecutados por sus captores (cosa que pasó en Europa, aunque no fue la norma). ${ }^{59}$ Durante sus largas campañas contra los federales en 1913-1914, los revolucionarios - tanto constitucionalistas como zapatistas - regularmente fusilaron a los oficiales presos, práctica que fue legitimada por la decisión draconiana del Primer Jefe, basada en el decreto de Benito Juárez de 1862. ${ }^{60}$ Por tanto, mientras que los soldados rasos del ejército federal, cada vez más conscriptos reclutados a la fuerza por la leva, fueron incorporados en el ejército revolucionario o simplemente desaparecieron en el creciente caos de la Revo-

58 Más adelante, en la nota 88, doy cifras de las bajas totales por países, es decir, las bajas sufridas debido a la guerra en su totalidad, 19141918. Calcular y comparar las bajas por batalla es más difícil, ya que las "batallas" del frente occidental -como la del Somme (nota 28)- duraron semanas y hasta meses. Una mejor comparación sería con el frente oriental, donde sí hubo batallas de corta duración: así, en agosto de 1914, un ejército alemán de 30000 perdió 8000 (27\%) "en una hora o dos" contra los rusos en la batalla de Gumbinnen, la primera de las llamadas "batallas de los lagos de Masuria", durante las cuales las bajas alemanas sumaron 40\% (100000/250 000), véase STONE, The Eastern Front, pp. 60-69. Hay que tomar en cuenta que estas "bajas" incluyeron gran número de prisioneros, fenómeno que se vio mucho menos en la revolución mexicana.

${ }^{59}$ Véase Ferguson, The Pity of War, cap. 13.

${ }^{60}$ Véase Ferguson, The Pity of War, cap. 13. 
lución, muchos oficiales fueron ejecutados: decían que Villa los alineaba en grupos de tres, para ahorrar parque (decían también que su compadre Rodolfo Fierro se deleitaba jugando al verdugo). ${ }^{61}$ Después de la caída de Chilpancingo en marzo de 1914, los zapatistas permitieron al general Cartón sepultar a su hijo, también soldado federal, que había muerto en la batalla, y en seguida lo fusilaron. ${ }^{62}$ Cartón mereció esta mala suerte porque tuvo fama de haber sido un comandante duro y sanguinario durante sus campañas en Morelos, al lado del infame Juvencio Robles; ${ }^{63}$ sobre todo, la conducta del ejército federal en muchas partes del país - la leva, la destrucción de pueblos, la ejecución de prisioneros (a veces por medio de la ley fuga) - fácilmente explica el maltrato que recibían al caer en manos de los rebeldes.

Esta conducta por parte de los federales fue típica de situaciones en donde un ejército regular se enfrentó a una proliferación de fuerzas irregulares, surgidas de la población civil y en general rural. Este patrón, muy conocido en contextos coloniales, fue la norma a principios de la Revolución y continuó durante años en el centro del país. Conforme este patrón se borró, la distinción entre civiles y militares (ya que, el campesino civil se volvió el guerrillero armado), y el ejército federal, bajo Huerta, Robles, y otros,${ }^{64}$ recurrió a medidas de contrainsurgencia, como quemar las comunidades, congregar a sus poblaciones y fusilar a sus prisioneros, medidas que habían sido utilizadas en luchas coloniales por los españoles en Cuba, los británicos en Sudáfrica y los

${ }_{61}$ Reed, Insurgent Mexico, p. 132; Thord-Grey, Gringo Rebel, p. 68.

${ }_{62}$ Olivera (coord.), Mi pueblo durante la Revolución, t. 2, p. 17.

${ }^{63}$ Womack, Zapata, pp. 175, 182.

${ }^{64}$ Wомаск, Zapata, p. 109. 
estadounidenses en las Filipinas. Es decir, aquí tenemos otra comparación internacional: la llamada "guerra asimétrica", diferente de la guerra en Europa, todavía muy feroz y costosa en términos de vidas, cosechas y animales. De hecho, Huerta, como presidente, buscó el consejo de su simpatizante, el ministro británico Lionel Carden, en cuanto a las tácticas usadas en la guerra de Sudáfrica. En el norte también, donde la guerra de guerrillas se volvió una guerra convencional más temprano, los comandantes federales cometieron abusos contra la población civil: el general Joaquín Maass, por ejemplo, amenazó con poner parientes de los líderes rebeldes, incluso las hermanas de Carranza, en las locomotoras, para evitar ataques contra la red ferroviaria, mientras que el general Pedro Ojeda - conforme el informe de Obregón - asesinó brutalmente a los prisioneros heridos. ${ }^{65}$

Pero tal represión draconiana sirvió para alentar a los rebeldes, mientras justificaba la práctica revolucionaria de ejecutar a los oficiales federales que caían en sus manos. Com-

${ }^{65}$ Pasztor, The Spirit of Hidalgo, p. 97; Obregón, Ocho mil kilómetros, t. 2, pp. 212-213. Según una versión oral, en la batalla de Celaya Obregón también puso mujeres y niños en la primera fila de su ejército como escudos humanos. Salas, Soldaderas in the Mexican Military y Myth and History, p. 47, citando al lugarteniente Ángel Jiménez. Tomando en cuenta el título del libro de Salas, esto me parece más mito que historia: no he encontrado ninguna corroboración de Obregón por supuesto no lo menciona, ni siquiera para negarlo. Obregón era un soldado muy profesional y cumplido; y, quizá más importante, tales escudos humanos hubieran sido un obstáculo para su propio ejército -su movilidad, su puntería y quizá su moral- más que una barrera contra los villistas. La versión oral, que aparece en Pérez, Kallas y Kallas (coords.), Those Years of the Revolution, p. 131, incluye otro "dato histórico" muy dudoso: que los villistas perdieron en parte porque Estados Unidos les habían vendido balas hechas de madera y aserrín. 
parada con la conducta de la guerra en Europa, donde los prisioneros generalmente fueron tratados con cierta legalidad, la lucha civil en México pareciera sucia y no civilizada. Sin embargo, el tratamiento de los soldados rasos también era diferente y quizá más humano. Como mencioné, los prisioneros federales eran incorporados en el ejército revolucionario o puestos en libertad, y la misma práctica se veía, quizá menos generalizada, durante las campañas entre villistas y carrancistas en 1915. Esta decisión respondió a dos consideraciones. En primer lugar, los revolucionarios se dieron cuenta de que el cuerpo de oficiales del ejército federal era leal a Huerta (con unas pocas excepciones, como Felipe Ángeles); los veían como traidores a Madero y debían ser derrotados y eliminados. Durante 1914-1915, el liderazgo villista se mostró más complaciente con los oficiales exfederales, lo que provocó cierta tensión entre los oficiales villistas de origen revolucionario. ${ }^{66}$ Los soldados rasos federales, por el contrario, eran reclutas renuentes, víctimas muchas veces de la leva, no tan diferentes, en cuanto a su clase social y origen étnico, de los propios rebeldes. No compartían ninguna lealtad colectiva al ejército regular. Además, ofrecerles a ellos no el paredón sino una bienvenida en los rangos revolucionarios fue una buena medida para aumentar el reclutamiento rebelde y, al mismo tiempo, socavar la moral federal. Así, la deserción masiva se volvió endémica hacia el verano de 1914; fenómeno menos frecuente en 1915, cuando dos ejércitos revolucionarios, es decir, compuestos principalmente de voluntarios, se enfrentaron. ${ }^{67}$

${ }^{66}$ Katz, The Life and Times of Pancho Villa, pp. 445-446.

67 Después de la batalla de Paredón, en mayo de 1914, más de 1000 fede- 
El segundo factor fue qué hacer con los prisioneros de guerra, lo que Ferguson llama el dilema del captor. ${ }^{68}$ En Europa, los campos de prisioneros surgieron en todos los países beligerantes para acomodar a los 8000000 de presos (24\% del total de bajas). ${ }^{69}$ En México, casi no existían: un caso bien conocido se encontró en Estados Unidos, en Fort Bliss, donde 3000 federales fueron alojados "en un vasto corral", dice John Reed, después de la derrota del general Mercado a manos de Villa en Chihuahua. ${ }^{70}$ En otras partes, la creación de campos de prisioneros hubiera sido imposible o irracional: hubieran consumido recursos, necesitado guardias militares, y representado potenciales retos detrás de las líneas. ${ }^{71}$ Para los rebeldes fue más práctico fusilar a los oficiales y liberar o reclutar a la tropa. Una consecuencia positiva es que la revolución mexicana, en contraste con la guerra civil estadounidense, no produjo ejemplos de encarcelamiento atroz que

rales fueron tomado prisioneros y muchos otros huyeron, abandonando sus uniformes; un sauve-qui-pent parecido ocurrió en Zacatecas un mes después. Katz, Life and Times of Pancho Villa, pp. 344, 350.

${ }^{68}$ Ferguson, The Pity of War, cap. 13.

${ }^{69}$ Ferguson, The Pity of War, p. 369. La mayoría fueron del frente oriental, es decir, rusos, austriacos, alemanes e italianos, donde la guerra fue mucho más móvil y fluida.

70 Reed, Insurgent Mexico, pp. 39, 44-5. Joseph y Buchenau, Mexico's Once and Future Revolution, p. 75, afirma, sin dar detalles ni cita, que los morelenses "fueron deportados en grandes cantidades a campos de prisioneros en Yucatán": creo que esto se refiere a los años 1913-1914 y la represión huertista. Wомаск, Zapata, p. 168, menciona la deportación de morelenses para servir en el ejército o trabajar en "estados donde faltan brazos". Parece poco probable que Yucatán hubiera sido su destino, ya que el movimiento revolucionario en la Península fue muy débil y no hubo escasez de brazos. El propio Joseph, Revolution From Without, no se refiere a ninguna presencia zapatista en la Península.

${ }^{71}$ En la medida en que había "líneas". 
involucraran altos niveles de privación y de mortalidad, como en el campo de Andersonsville, Georgia. ${ }^{72}$

\section{III}

Al tratar la severidad de la guerra revolucionaria, he mencionado varias fases del conflicto. Ahora quiero profundizar un poco apuntando cuatro fases de la revolución armada (19101920): 1) la breve revolución contra Díaz, un periodo de seis meses, 1910-1911, que ostentó un patrón de conflicto violento que continuó, mutatis mutandis, bajo Madero en 1911$1913 ; 2$ ) las revoluciones constitucionalista y zapatista contra Huerta, 1913-1914;3) la "guerra de los ganadores" entre Villa y Carranza durante 1914-1915, y 4) entre 1915 y 1920 la larga lucha del frágil régimen constitucionalista/carrancista contra una gran variedad de fuerzas rebeldes: villistas, zapatistas, felicistas, pelaecistas, oaxaqueñas, mapaches, etc., fuerzas que podían desafiar al gobierno central sin lograr derrocarlo. Estas fases muestran diferentes formas de conflicto y, quizá, diversos aspectos psicológicos en cuanto a la conducta de la guerra (total). Voy a analizar las primeras tres, mencionando la última (1915-1920) brevemente.

1) La primera fase de rebelión involucró una gama de pequeñas fuerzas revolucionarias, nominalmente encabezadas por Madero, contra el ejército federal y los cuerpos rurales del antiguo régimen (ambas fuerzas gozaron de una buena,

72 Construido para una población de 10000 , Andersonsville alojó a 33000 presos, de los cuales 13000 murieron a causa del mal trato. Después de la guerra, el comandante del campo, Henry Wirz, fue ahorcado como criminal de guerra. Gates, Wafare in the Nineteenth Century, p. 148. 
pero inflada, reputación, cuyo padrón - en el caso del ejército - había disminuido a través de los años, y que se habían vuelto algo corruptas y complacientes durante la larga paz porfiriana). ${ }^{73}$ La opinión general era que rebelarse contra Díaz era fútil y, de hecho, muchas de las rebeliones iniciales de 1910 fueron aplastadas, como lo habían sido muchas en el pasado. ${ }^{74}$ Sin embargo, durante el invierno de 1910-1911 brotaron algunos "focos" revolucionarios, sobre todo en el norte: en la Sierra Madre Occidental de Chihuahua y en La Laguna; y pronto surgieron otros en el centro del país, como Morelos, y después Puebla, Tlaxcala y Guerrero. El sur del país permaneció más tranquilo. Este patrón geográfico dependió de factores de empuje (quejas populares, políticas y sociales, que se encuentran fuera del alcance de esta investigación) y condiciones facilitadoras, por lo cual quiero decir que la capacidad de ciertas regiones y personas para alzarse en armas contra Díaz (o sus representantes locales). La resistencia necesitó liderazgo, organización, y acceso a las armas y a los medios de transporte, es decir, inicialmente, caballos y mulas. No es de sorprender que las antiguas colonias militares de Chihuahua, nacidas para pelear y experimentadas en las guerras contra los “indios bárbaros” hasta la década de 1880, desempeñaran un papel clave, como enfatizó Friedrich

73 Portilla, Una sociedad en armas, p. 398, da cifras de 29000, con una fuerza activa de 25000 , aunque hay razones para creer que este número es una sobreestimación, debido a la antigua práctica de inflar el padrón: Portilla, Una sociedad en armas, p. 400, citando a José R. del Castillo; véase también Ramírez RancaÑo, "Una discusión sobre el tamaño del ejército mexicano, pp. 35-71; y sobre los rurales, unos 3000 , VANDERWOOD, Disorder and Progress.

${ }^{74}$ Knight, Mexican Revolution, t. 1, pp. 172-175; Portilla, Una sociedad en armas, pp. 90-91. 
Katz. ${ }^{75}$ Generalmente, las comunidades "serranas" - comparadas con muchas - estaban fuera del alcance del régimen y de su ejército y albergaron una población básicamente de hombres (en 1910-1911 había pocas soldaderas) acostumbrados a viajar por las montañas y a utilizar armas: arrieros como Orozco, bandidos como Villa y Urbina, amén de líderes de comunidades (no serranas) en pugna con las autoridades o los hacendados locales (Calixto Contreras de Cuencamé, Toribio Ortega de Cuchillo Parado), es decir, en la frase italiana, "hombres que se hacen respetar". Sin embargo, aun estas comunidades/líderes carecían de armas y parque: hay reportes de los rebeldes pioneros de 1910-1911 llevando antiguos mosquetes, escopetas, machetes, cuchillos, y hasta arcos y flechas y garrotes de madera. ${ }^{76} \mathrm{El}$ arma más común y codiciado era el legendario Winchester. 303, tradicionalmente un arma de caza, que era de corto alcance y tendía a calentarse si se usaba mucho; el Mauser de los federales era, en este sentido, superior. No obstante los esfuerzos de ciertos líderes revolucionarios (como Gustavo A. Madero) para conseguir armas en Estados Unidos, las rebeliones iniciales, aun en el

75 Katz, Life and Times of Pancho Villa, pp. 12-17 y 251; Portilla, Una sociedad en armas, cap. 5 ofrece una valiosa narrativa de los principios de la Revolución en Chihuahua.

76 KNight, Mexican Revolution, t. 1, pp. 189-190, 198-199; Portilla, Una sociedad en armas, pp. 355-356; Olivera (coord.), Mi pueblo en tiempos de la Revolución, t. 3, p. 12, donde la gente de Tampamolón, en la Huasteca, se acuerda de los rebeldes pioneros de 1910-1911 como "un ejército de voluntarios, armados de hondas, flechas, macañas, machetes, cuchillos, hachas y toda clase de herramientas de trabajo. El único arma de fuego que contaron al principio fue la llamada carabina chachalaquera". En el Istmo de Tehuantepec los maderistas carecían de armas de fuego: "solo había machetes, palos, hondas, [y] puyas": OliveRA (coord.), Mi pueblo en tiempos de la Revolución, t. 2, p. 78. 
norte, estuvieron muy mal abastecidas y dependieron de las armas que ya tenían los rebeldes o las que pudieron arrancar de las haciendas y, eventualmente, de los propios federales (notablemente el fusil Mauser $7 \mathrm{~mm}$ ). ${ }^{77}$ De hecho, una prioridad, al principio, fue buscar armas por medio de asaltos en las haciendas y campos mineros. Mientras que, gracias a su conocimiento del terreno y el apoyo popular, los rebeldes podían sostener una campaña guerrillera en las sierras - donde el ejército federal fue renuente a entrar y los célebres rurales se mostraron ineficaces -, no podían enfrentarse a los federales en plena batalla; cuando 600 rebeldes, bajo Madero, se lanzaron contra 500 federales en Casas Grandes, fueron derrotados, en parte debido a la artillería del enemigo. ${ }^{78}$ Hacia el sur, el progreso de la Revolución fue aún más lento y difícil por las mismas razones.

Sin embargo, no obstante su debilidad en cuanto a materia bélica, la Revolución tuvo éxito en el sentido de desafiar al gobierno y tener un impacto en gran parte del norte y el centro del país. El campo se volvió cada vez más terreno insurgente, mientras que los federales controlaron las ciudades y la red ferroviaria. Sin tener ametralladoras ni artillería, los rebeldes no podían tomar las ciudades, pero, gracias a la simpatía general por la Revolución, las fuerzas del gobierno no podían - en cierto sentido no querían - reconquistar el campo. ${ }^{79}$ Hacia la primavera de 1911 el resultado fue tablas, al menos en el norte y gran parte del centro del país. En mayo los revolucionarios

\footnotetext{
77 Portilla, Una sociedad en armas, pp. 323-326

78 Portilla, Una sociedad en armas, pp. 96-97; Knight, Mexican Revolution, t. 1, p. 187.

${ }^{79}$ Sobre la simpatía por la Revolución, observada por los representantes estadounidenses, véase Knight, Mexican Revolution, t. I, pp. 182, 194.
} 
tomaron Ciudad Juárez - la única ciudad norteña tomada a fuego - y la moral federal se marchitó (de ahí, su evacuación de Torreón y Chilpancingo); en seguida comenzaron las pláticas que condujeron al Tratado de Ciudad Juárez (21 de mayo de 1911). La élite política porfirista decidió sacrificar a Díaz para mantener su propia autoridad, mientras que Madero temía que la Revolución que él había comenzado se escaparia totalmente de su control. ${ }^{80}$ Probablemente Madero se dio cuenta también que derrotar al ejército federal, atrincherado en sus fuertes posiciones, con ametralladoras y artillería, significaba una guerra mucho más larga y violenta, con consecuencias sociales (y humanas) que Madero - ingenuo pero humanitario - quería evitar. La Revolución había alcanzado parcialmente el objeto clausewitziano de imponer su voluntad sobre el enemigo en el sentido de derrocar a Díaz, pero quedó la estructura del antiguo régimen, y también se mantuvo, en palabras del poeta, el ejército federal se mantuvo "sangriento pero erguido". ${ }^{81}$

Como la historia del interinato del presidente De la Barra y de la frágil administración de Madero demuestra, el legado de la transacción hecha en Juárez fue muy ambiguo: México adquirió un régimen algo democrático, pero el aparato represivo del antiguo régimen sobrevivió como sostén del orden social porfiriano, mientras que las fuerzas revolucionarias, rápida y caóticamente movilizadas en 1910-1911, fueron licenciadas o, en ciertos casos, incorporadas en los rurales. No consiguieron lo que merecieron por sus esfuerzos y sacrifi-

${ }^{80}$ La toma de Juárez fue llevada a cabo contra las órdenes de Madero, que temía las consecuencias para El Paso.

${ }^{81}$ Traducción no muy poética de la línea de William E. Henley: "under the bludgeoning of chance / my head is bloody but unbowed" ("apaleada por la suerte / mi cabeza está sangrienta pero erguida"). 
cios, y no estaban dispuestos a regresar a casa y entregar sus armas y caballos (muchas veces recién adquiridos). El ejército federal no sólo mantuvo su supuesto "monopolio de la violencia legítima”, 82 sino que fue aumentado y reforzado por Madero, que dependió cada vez más de él para enfrentar a los orozquistas y zapatistas, amén de un sinnúmero de gavillas de rebeldes/bandidos rurales. El patrón de guerra asimétrica, evidente en 1910-1911, reapareció (de hecho, nunca había desaparecido): en el norte, los federales, después de una inicial derrota desastrosa, ${ }^{83}$ pudieron vencer a los orozquistas, pero en otras partes, especialmente pero no sólo Morelos, no pudieron eliminar a los guerrilleros zapatistas y otros y, por tanto, recurrieron a las medidas represivas ya mencionadas. Pero los guerrilleros todavía carecían de armas, parque y artillería (en cantidades suficientes para enfrentarse a los federales en plena batalla), y, debido a su íntima relación con los pueblos, estaban constreñidos por el inexorable ciclo de las lluvias, la siembra y la cosecha. ${ }^{84}$

2) Por fin, el cuartelazo de febrero de 1913 - la primera vez que la ciudad de México sufrió seriamente la violencia revolucionaria - puso fin a la ambigua administración maderista y marcó los inicios de una nueva ecuación militar. Huerta

82 Un monopolio algo teórico, jamás completo, aún en tiempos de Díaz. 83 Derrota (Rellano) causada en parte por el ingenio de los rebeldes (su uso de la "máquina loca" -el tren explosivo), en parte por la falta de capacidad del comandante federal, que en seguida se suicidó. La subsecuente campaña de Victoriano Huerta demostró que los federales todavía tuvieron muchas ventajas en batallas convencionales.

84 Knight, Mexican Revolution, t. 1, pp. 277, 315, 318, 378; Herrera Sipriano, La Revolución en la montaña de Guerrero, p. 104. 
decepcionó a sus aliados civiles (como Félix Díaz) y comenzó a construir una dictadura militar y a imponer la paz, costara lo que costara. ${ }^{85} \mathrm{El}$ ejército federal creció enormemente, siendo diez veces mayor en 1914 que lo que había sido en $1910 .{ }^{86}$ En ese año quizá uno de cada 600 mexicanos era soldado federal; cuatro años después fue uno de cada $60 .{ }^{87}$ Además, este cálculo sólo incluye a los federales. Si suponemos un número igual de soldados revolucionarios, sería un soldado por cada 30 mexicanos, lo que quiere decir que entre $15 \%$ y $20 \%$ de los hombres adultos capaces de portar armas lo eran. ${ }^{88} \mathrm{El}$ gasto militar subió (en qué medida no lo sabemos),

85 Langle Ramírez, El militarismo de Victoriano Huerta; Knight, Mexican Revolution, t. 2, cap. 1.

${ }^{86}$ Es decir, 250000 contra 25000 . Ramírez Rancaño, "Una discusión sobre el tamaño del ejército mexicano", p. 61.

${ }^{87}$ Claro, todas estas cifras son aproximadas. En particular, el padrón del ejército federal fue aumentado por la corrupción, una antigua práctica: véase la nota 73 .

${ }^{88}$ De hecho, me parece probable que hubiera mayor número de rebeldes que federales que contrarrestaría el bias mencionado en la nota 87. "Hombres adultos capaces de portar las armas" es, por supuesto, una categoría vaga; calculo que representa como máximo $20 \%$ de la población. Por supuesto, si incluimos a las soldaderas -la mayoría no combatienteslas cifras de la militarización social serían aún mayores. Si comparamos la cifra mexicana (alrededor de 3.3\% de la población en armas en 1914), vemos que es la mitad de la cifra alemana para 1915 (6.6\%); pero Alemania -y las demás potencias centrales- reclutaron un porcentaje mucho mayor de su población que los aliados (que tenían enormes reservas demográficas en Rusia y el Imperio Británico): el porcentaje para Rusia (1915) fue nada más $1 \%$ (1.8m en una población de $170 \mathrm{~m})$ : Ferguson, The Pity of War, pp. 267, 298; Ferro, The Great War, p. 62. Otra comparación sugerente sería Italia, donde el ejército en 1917, año de la desastrosa derrota en Caporetto, sumó a 2500000 personas, es decir, $5.4 \%$ de la población total. Se ve que el porcentaje mexicano no es radicalmente distinto de las cifras europeas. 
generando un peso fiscal que el gobierno de Huerta no pudo sostener, especialmente conforme iba perdiendo control del territorio, los centros de producción y los puertos aduaneros. ${ }^{89} \mathrm{El}$ peso mexicano se debilitó, la inflación cobró fuerza, y México abandonó el patrón oro (que había adoptado apenas unos siete años antes). El costo de la guerra fue en realidad mayor, porque los ejércitos, tanto federal como revolucionario, tuvieron que vivir de los recursos del país: de ahí las quejas de robo de ganado y cosechas. ${ }^{90}$ En términos políticos, el gobierno civil fue destrozado, con generales reemplazando a gobernadores; la élite maderista fue purgada (a veces asesinada) y en octubre de 1913 el Congreso fue cerrado forzosamente. Para alcanzar una supuesta estabilidad neoporfiriana, Huerta estableció un régimen mucho más militar que el porfiriato. A mi modo de ver, esto fue un proyecto fútil, quizá aún menos real que el compromiso liberal democrático de Madero. ${ }^{91}$ Su base social fue demasiado estrecha, su fe en la coerción como solución demasiado ingenua; aunque era un general capaz y experimentado (experimentado, al menos, en campañas de represión contra rebeliones indígenas), Huerta careció de habilidad política; fue un ejemplo, tal vez, de lo que

89 Wilkie, The Mexican Revolution, pp. 100-102, ofrece sólo cifras del presupuesto militar proyectado para 1913-1914 (31\% del presupuesto total, es decir, aproximadamente $50 \%$ mayor que en el último año del porfiriato); es seguro que el gasto actual fue mucho mayor.

90 Incluso en el Distrito Federal, San Miguel Xicalco, "en la época de los elotes, los soldados que siempre andaban por allí, se robaban elotes precisamente los elotes y por las noches hasta los animales que algunos campesinos tenían". Olivera (coord.), Mi pueblo en tiempos de la Revolución, t. 1, p. 26.

${ }^{91} \mathrm{Y}$ no porque Estados Unidos estaba en contra. Eso sí fue un factor pero secundario. 
Norman Dixon llama "la psicología de la incapacidad militar" " the psychology of military incompetence"), es decir, un modo de pensar estrecho y sin imaginación (características que él compartía con varios generales europeos de la primera guerra mundial: Haig, Joffre y Von Falkenhayn). ${ }^{92}$

Sin embargo, las debilidades del régimen huertista no se vieron de inmediato. Los oficiales federales le fueron leales en la mayoría de los casos y no carecieron de habilidad e inteligencia militar. ${ }^{93}$ Tuvieron éxitos iniciales, por ejemplo en el noreste, y aun cuando la marea se volvió contra ellos, el ejército federal mantuvo una resistencia tenaz en Torreón (marzo-abril de 1914). ${ }^{94}$ Mientras que es difícil analizar los motivos de los oficiales federales (los ganadores escriben la historia y, que yo sepa, hay pocas memorias hechas por

92 Dixon, On The Psychology of Military Incompetence. Dixon trata la incapacidad militar principalmente en cuanto a la prosecución de la guerra; en el caso de Huerta, es su actuación política que resultó incapaz y, por tanto, contraproducente. Sin embargo, en ambos casos vemos el mismo fenómeno: un modo de pensar rígido, autoritario y renuente al cambio o a la innovación: véase Ferguson, The Pity of War, pp. 303-310. Vale mencionar que, con motivo del centenario de la primera guerra mundial, hay cierta tendencia historiográfica para revisar la reputación de generales como Haig, justificando su pródigo desperdicio de vidas; revisión que no es nada nueva y tampoco convence mucho: véase Sheffield, The Chief, que sigue la antigua pista de Terraine, Douglas Haig. Vale acordarnos de otra opinión sarcástica de Haig que fue el general escocés que mató más ingleses que cualquier otro; desafortunadamente, ellos pertenecían a su propio ejército

${ }_{93}$ Hay opiniones en contra, véase la nota 52.

${ }_{94}$ Un buen ejemplo sería el formidable contraataque llevado a cabo a las 5 de la mañana del 29 de marzo de 1914 por los federales para recuperar los fuertes de Santa Rosa y Calabazas, en las afueras de Torreón, que los rebeldes acabaron de tomar a fuerza y sangre, GonzÁLEz GARZA, Ramos Romero y Pérez Rul, La batalla de Torreón, p. 29. 
oficiales huertistas), creo que involucraron una preferencia colectiva por el antiguo régimen; preferencia compartida por una minoría de mexicanos de la clase acomodada, y por la mayoría de extranjeros en México, aunada a una lealtad más enfocada al ejército, y quizá a su propio regimiento. Pero, en contraste con Europa, esta lealtad no fue compartida por los soldados rasos del ejército federal.

Los federales gozaron de ventajas y desventajas. Tuvieron acceso a las armas, acceso que continuó aún después del boicot impuesto por el gobierno de Estados Unidos en febrero. Es decir, de febrero a octubre de 1913 (ocho meses), los federales podían importar grandes cantidades de armas y parque del norte, mientras que los rebeldes no tuvieron acceso (legal) a este mercado. En octubre Estados Unidos impuso su boicot a todas las facciones, y en febrero de 1914 permitió la importación de armas por parte de los revolucionarios. Es decir, durante un año los federales o gozaron de una ventaja en cuanto al mercado estadounidense, o al menos estaban en la misma situación que sus contrincantes. El apoyo estadounidense a los rebeldes llegó un año después del cuartelazo, lo que pone en tela de juicio la idea de que Estados Unidos fue el autor de la caída de Huerta. ${ }^{95}$ En 1914, Huerta podía importar de Europa y Japón. ${ }^{96}$ La evidencia, entonces, es clara: durante 1913-1914 los federales estaban mejor armados y abastecidos que los rebeldes, especialmente en cuanto

\footnotetext{
${ }_{95}$ Grieb, The United States and Huerta, discrepa.

${ }^{96}$ Hacia fines de 1914 el estallido de la guerra en Europa hizo subir los precios de las municiones entre $35 \%$ y $70 \%$ conforme KaTz, The Life and Times of Pancho Villa, p. 489; sin embargo, esto afectó a todas las facciones en México por igual; además, la caída de Huerta coincidió con la crisis de julio-agosto de 1914.
} 
a la artillería y las ametralladoras. Aún en 1914 hay poca evidencia de los federales perdiendo batallas debido a su falta de parque; lo que se ve, en la primavera y verano de ese año, es el quiebre de su sistema de comunicaciones, de tal manera que las municiones que tenían no podían llegar al frente (por ejemplo, en el noreste). ${ }^{97}$

Sin embargo, las armas deben ser utilizadas; aunque los federales tuvieron una organización militar coherente y, entre los oficiales cierto sentimiento corporativo, los soldados rasos eran muy diferentes. El gran crecimiento del ejército - aun si las cifras fueron infladas por la corrupción-dependía en esencia del reclutamiento forzoso, es decir, la antigua práctica de la leva, que tuvo una larga y odiada historia en México y que, bajo el mandato Huerta, se volvió más extensa que nunca. Los jóvenes (y los no tan jóvenes) fueron reclutados en las calles del Distrito Federal, cuando salían de los cines o de las corridas de toros; en Veracruz se llevaron a los limpiabotas, y en la capital, los tranviarios avisaban a sus cuates no bajar en ciertas paradas, donde esperaban los sargentos reclutadores. ${ }^{98}$ La leva se resintió y provocó rebeliones, incluso en regiones como la Sierra Norte de Puebla donde, hasta ahora, la Revolución no había echado raíces. ${ }^{99}$ Y, por supuesto,

${ }_{97} \mathrm{La}$ correspondencia entre los generales Maass y Massieu, Monterrey y Saltillo, en abril de 1914, sugiere que no les faltaban fuerzas y municiones, por tanto todavía podían conseguir victorias contra grupos de rebeldes locales; sin embargo, las comunicaciones eran cada vez más difíciles, las líneas ferroviarias habían sido cortadas por los rebeldes y reinaban tanto confusión como incertidumbre. Olivera (coord.), Mi pueblo en tiempos de la Revolución, t. 1, pp. 50-58.

98 Knight, Mexican Revolution, t. 2, pp. 78-79; véase también OliveRA (coord.), Mi pueblo en tiempos de la Revolución, t. 1, p. 31; t. 2, p. 16. 99 Knight, Mexican Revolution, t. 2, pp. 55-56; LAFrance, Revolution in Mexico"s Heartland, pp. 40-41. 
los conscriptos fueron soldados renuentes e incapaces. Los oficiales temían salir al campo abierto con sus tropas lo que explica, en parte, la estrategia estática y defensiva de los federales; $y$, durante las batallas, los oficiales se quedaban atrás, se dijo, listos para disparar contra soldados cobardes. ${ }^{100}$ No es de sorprender, entonces, que cuando se enfrentaron a fuerzas rebeldes cuya moral era muy superior, las tropas federales parecieron débiles e incapaces; y la disposición de los revolucionarios de aceptar a los exfederales en sus rangos fomentó la deserción masiva, sobre todo en 1914. Esto demuestra un aspecto clave de la Revolución que algunos historiadores revisionistas quizá han subestimado: el hecho de que los ejércitos revolucionarios eran fuerzas voluntarias que, en 1913-

100 Este fenómeno se veía también en Europa, especialmente en el frente oriental, donde el ejército ruso, como el federal mexicano, era una fuerza de campesinos mal entrenados y, a veces, reclutados a la fuerza al mando de oficiales corruptos, despectivos y brutales que "trataban a sus soldados como siervos". Stone, The Eastern Front, pp. 168-171; Ferguson, The Pity of War, p. 347. De ahí, en parte, los motines y finalmente la revolución de 1917. En el frente occidental también hubo motines (por ejemplo en el ejército francés en el verano de 1917), pero fueron pocos, en parte porque los oficiales gozaron de mayor autoridad y hasta respeto; $y$ los oficiales (de menor rango) encabezaban la carga, a veces suicida, lo que explica las altas cifras de mortalidad entre estos oficiales (los subalternos) en el ejército británico. Ferguson, The Pity of War, pp. 201202, 345-346. Junger, The Storm of Steel ofrece un ejemplo autobiográfico alemán. En México, recordaremos que Villa tomó parte activa en sus batallas, mientras que Obregón perdió su brazo derecho cuando ocupaba una posición muy avanzada -y por tanto vulnerable- a principios de la batalla de Trinidad: cosa que Haig, Joffre o Falkenhayn nunca hubieran hecho. Y tanto Villa como Obregón tenían fama de codearse con sus tropas, bailando toda la noche (en el caso de Villa) o, en el caso de Obregón, contando "las anécdotas, y los hechos a todo color". REED, Insurgent Mexico, pp. 159-160; Alessio Robles, Obregón como militar, p. 5. 
1914, combatían contra un ejército de conscriptos. Es cierto que aquéllos pagaron sueldos a sus soldados - los sonorenses desde el principio de su campaña, en 1913, los zapatistas también, conforme sus tropas fueron creciendo-, pero los sueldos no fueron incentivos para alistar y pelear; más bien fueron desincentivos contra el pillaje de los civiles (aspecto clave para todo ejército popular revolucionario, como bien enfatizó Mao). Este contraste en cuanto a la moral fue crucial, particularmente en 1913, cuando los federales gozaron de grandes ventajas en términos de armas; y, como dijo Napoleón en uno de sus mejores dichos: "en la guerra, la moral vale tres veces más que lo material”. ${ }^{101}$ En otras palabras, su moral permitió a los rebeldes aguantar la superioridad material de los federales hasta que, en la primavera de 1914, ésta se esfumó.

Por el lado revolucionario, este proceso involucró un salto cuántico en términos de organización militar. Tuvieron que hacer la difícil transición de la guerra de guerrillas descentralizada, librada por pequeñas fuerzas móviles (es decir, montadas), que "pegaron y huyeron", y que evitaron las batallas convencionales, a una forma de pelear convencional, que incluyó asedios y batallas en campo abierto. En sus iniciales escaramuzas en el noreste, Carranza, como Madero en Casas Grandes, perdió contra los federales y tuvo que hacer su larga y peligrosa odisea hacia el noroeste, donde los sonorenses se mostraron como los pioneros de la nueva forma de movilización militar. Los sonorenses, más lejanos y aislados del centro, gozaban de una antigua tradición de autodefensa, tenían fuerzas estatales reclutadas para combatir a los oroz-

${ }^{101}$ Howard, War in European History, p. 106. 
quista en 1912, y, aunque todavía no lo sabían, en Álvaro Obregón tenían al gran genio napoleónico de la Revolución. Ahora bien, sin la organización militar y administrativa de los sonorenses, el genio de Obregón hubiera quedado oculto; esto permitió la transición a un ejército convencional, dotado de armas que fueron importadas ilegalmente de Estados Unidos, pagadas con la exportación minera y ganadera. ${ }^{102}$

En Chihuahua también ocurrió este proceso de profesionalización militar, aunque más lentamente que en Sonora. Aquí, por supuesto, el gran caudillo fue Pancho Villa, que sin la ayuda de un gobierno estatal en función construyó un ejército convencional, la célebre División del Norte, que jugó un papel central, tanto geográfica como estratégicamente, en la derrota del ejército federal. ${ }^{103}$ En el centro del país, donde el control federal era más fuerte, el proceso tardó aún más: Zapata luchó para organizar una fuerza capaz de enfrentarse a los federales en batalla y de tomar ciudades clave como Cuautla, Cuernavaca y Chilpancingo; pero su ejército nunca alcanzó ese grado de profesionalización que caracterizó a los ejércitos del norte. Los zapatistas quedaron más arraigados a su patria chica, Morelos y los estados vecinos, más ligados a sus pueblos y al ciclo agrícola, por tanto renuentes a alejarse demasiado en largas campañas al estilo villista u obregonis-

102 Aguilar Camín, La frontera nómada, cap. 6.

103 No hay que olvidar el ejército del noreste, encabezado por el general Pablo González: véase las memorias de GonzÁlez, Contra Villa: relatos de la campaña, 1914-1915, p. 19, donde demuestra que, no obstante su mediocre reputación entre los historiadores, aún González "el viejo” gozaba de enorme respeto entre sus lugartenientes; conforme esta versión, parece que el consumo de grandes cantidades de buen coñac contribuyó al feliz ambiente de camaradería. Además, varios oficiales eran miembros de la misma logia masónica (de Monclova). 
ta. ${ }^{104} \mathrm{Y}$ otras fuerzas del centro y sur del país - los serranos o los poblanos o los oaxaqueños, por ejemplo- se mostraron aún más limitadas en sus horizontes políticos y capacidades militares.

Dos factores, uno sociopolítico, el otro logístico, explican este contraste entre los ejércitos más profesionales y móviles norteños, y las fuerzas más parroquiales del centro y sur. ${ }^{105}$ Los ejércitos del norte eran una mezcla de grupos sociales muy diversos: campesinos (serranos y agraristas), miembros de la clase media "decente", obreros, sobre todo mineros, ferrocarrileros y trabajadores de las compañías madereras, además de una minoría de indígenas (yaquis y mayos en Sonora, tarahumaras en Chihuahua) y célebres bandidos, como Villa y Urbina. Eran producto de una sociedad móvil y comercial y tenían metas y motivos diversos. Por eso, podían formar parte de grandes ejércitos convencionales, supralocales, y listos para andar de campaña en tierras extrañas (recuérdese Ocho mil kilómetros en campaña de Obregón). Hacia 1914-1915 las tropas yaquis eran un espectáculo frecuente y preocupante en las calles de la capital. ${ }^{106}$ En contraste, los zapatistas quedaron ligados a sus pueblos y el ciclo agríco-

104 Womack, Zapata, pp. 225-228.

105 En este contexto sería posible utilizar la sugerente metáfora de “coyotes" (líderes móviles, de horizontes amplios) y "nopales” (los que se aferraban a sus patrias chicas), propuesta por Christopher R. Boyer, "The Coyotes and the Nopales: Caciquismo, Popular Movements, and State Consolidation in Michoacán, Mexico, 1917-1934”, ponencia dada en el Congreso Internacional de la Asociación de Estudios Latinoamericanos, marzo de 1994.

106 Para un ejemplo extraño (un capitalino fastidiado por el onanismo público de un pelotón yaqui), véase Rodríguez Kuri, Historia del desasosiego, pp. 135-136. 
la (de ahí cierta correlación entre este ciclo y sus campañas), mientras que los norteños se habían liberado de estas constricciones. Al mismo tiempo, Zapata estaba consciente de su responsabilidad frente a los pueblos de Morelos y, como sus tropas, no estaba dispuesto a emprender campañas lejos de su patria chica; por lo tanto, la alianza Villa-Zapata no fue muy eficaz. No le gustó para nada la ciudad de México. ${ }^{107}$

En segundo lugar, la guerra convencional necesitó un gran y fiable abastecimiento de armas y parque. A lo largo de 1913 los rebeldes sufrieron de la falta de ambos. Aún en el norte, cerca de la frontera, entraron en batalla peligrosamente mal pertrechados, en especial en cuanto a la artillería y las ametralladoras. En las escaramuzas iniciales de 1913, el objeto principal, como en 1910-1911, fue conseguir armas, o de las haciendas y compañías mineras, o de los propios federales quienes, derrotados, tenían la mala costumbre de dejar cantidades de armamento en el campo de batalla. Los rebeldes dependían todavía del Winchester. 303 (inferior al Mauser de los federales) y, careciendo de artillería, tenían que improvisar, por ejemplo, fabricando bombas de dinamita, tarea para los exmineros, o utilizando estratagemas como la célebre "máquina loca". ${ }^{108}$

107 Womack, Zapata, pp. 219, 240 y 242.

108 Sobre los “bomberitos" zapatistas, Olivera (coord.), Mi pueblo en tiempos de la Revolución, t. 2, p. 12. La máquina local tuvo su mayor éxito en la primera batalla de Rellano (1912), cuando los rebeldes orozquistas derrotaron a los federales. Pero fue utilizado en otras: en Tierra Blanca (1913), cuando Fierro, antiguo ferrocarrilero, capturó una locomotora y la envió contra el ejército federal: "la explosión fue tremenda pero el impacto desmoralizador sobre el enemigo fue aún peor”; y en El Ébano, donde Treviño, al mando de los carrancistas, hizo "que una góndola cargada de dinamita fuera lanzada a gran velocidad” sobre los villis- 
Villa hizo grandes esfuerzos para aumentar su deficiente artillería, al reclutar al soldado/mercenario sueco I. ThordGray, oficial de caballería convertido, a regañadientes, en experto en artillería del ejército villista. En el noroeste, Obregón dependió no sólo de sus fuerzas yaqui y mayo, sino también de su arma tradicional, el arco y las flechas, que resultaron muy eficaces en el desértico monte del noroeste; los tambores yaqui también tuvieron un fuerte efecto psicológico entre los conscriptos federales. ${ }^{109}$ Durante casi un año, como mencioné, Estados Unidos mantuvo un embargo contra la exportación de armas a los rebeldes, por tanto éstas tenían que ser llevadas a la frontera de manera clandestina (por ejemplo, en ataúdes), lo que aumentó considerablemente su precio en el mercado negro. ${ }^{110}$ Por fortuna los revolucionarios norteños tenían recursos que podían exportar para cubrir el costo, sobre todo ganado y productos minerales vendidos a precios bajos; es decir, los rebeldes fueron doblemente perjudicados debido a su comercio clandestino. ${ }^{111}$ No obstante, tanto Obregón como Villa pudieron abastecer ejércitos convencionales respetables para emprender el avance hacia el sur. Cuando en marzo de 1914, la División del Norte llegó a Torreón, un mes después de que Estados Unidos permitiera la exportación legal de armas, tenía quizá 15000 soldados además de soldaderas y niños, trenes blindados, carros sanita-

tas, destruyendo así un fuerte, un puente y "gran parte" de la línea ferroviaria, y "causando muchas bajas": Thord-Grey, Gringo Rebel, pp. 46-47; Barragán Rodríguez, Historia del ejército constitucionalista, t. 2, pp. 567-568.

109 Thord-Grey, Gringo Rebel, pp. 93-95, 100-101, 125.

110 Knight, The Mexican Revolution, t. 2, pp. 30-31.

111 Thord-Grey, Gringo Rebel, p. 108. 
rios, ametralladoras, cañones y artillería pesada ( $E l N i \tilde{n} o$ y $E l$ Chavalito), manejados por los 300 artilleros de Felipe Ángeles. ${ }^{12}$ Zapata y los rebeldes del centro carecían de estos recursos: se encontraban lejos de la frontera, no podían importar municiones por mar, y tampoco tenían fondos comparables con qué comprar lo que necesitaban. Tuvieron que restar sus armas de los federales (o fabricarlas en casa), lo que limitó considerable de forma su capacidad bélica. ${ }^{113}$

El gran éxito militar de la Revolución fue desafiar al gobierno y al creciente ejército de Huerta, aun cuando no tuvo acceso legal a las importaciones, mientras que convirtió una gama de fuerzas locales, irregulares, en ejércitos convencionales y capaces: un reto que necesitó recursos, organización y habilidad político militar. Los líderes, producto de la meritocracia informal de la Revolución, aceptaron el reto; y una vez levantado el boicot estadounidense, pudieron comenzar su avance de tres puntas hacia la ciudad de México. La gran victoria en Torreón fue seguida por otras en San Pedro, Zacatecas y Orendáin. La guerra asimétrica ahora se volvió convencional, con grandes batallas y (cortos) asedios. ${ }^{114}$ Incluso los zapatistas armaron un ejército de 5000 hombres

112 Katz, Life and Times of Pancho Villa, cap. 8; Knight, Mexican Revolution, t. 2, pp. 141-142; REeD, Insurgent Mexico, p. 133.

113 Todavía en 1914, Zapata carecía de armas y lo encontramos disputando con otro jefe la posesión de seis rifles, Womack, Zapata, p. 181. Recordemos que en 1919, Zapata cayó en la emboscada donde perdió la vida debido a su deseo de adquirir armas y refuerzos de sus enemigos (en ese entonces carrancistas). Wомаск, Zapata, pp. 323-324.

114 Como en la primera guerra mundial, hubo relativamente pocos asedios a ciudades o fortalezas durante la Revolución; la gran excepción -europea- fue Verdun. Horne, The Price of Glory. 
para tomar Chilpancingo (con una guarnición de 1400 federales) en abril. ${ }^{115}$

Ahora, en la primavera de 1914, la guerra en México se parecía cada vez más a lo que tendría lugar en Europa más tarde en el mismo año. Había grandes ejércitos (tomando en cuenta el tamaño relativo de la población), bien organizados y pertrechados, constando de tres categorías: infantería, caballería y artillería. Otra vez reitero mi cuestionamiento a esos historiadores que ven la guerra en México como algo folklórico, una "fiesta de balas" no tan seria ni mortífera. Aunque eran grandes, los ejércitos se construyeron a base de contingentes locales, regionales y personales: brigadas llevaron los nombres de sus líderes o de su lugar de origen, mientras que el ejército de Obregón, el que ganó la batalla de Celaya en 1915, siempre tuvo un fuerte núcleo sonorense. ${ }^{116}$ Otra vez, este fenómeno se ve en Europa (es otro punto de semejanza, no de diferencia): de ahí los regimientos regionales de Inglaterra y de Alemania, o los llamados "batallones de los camaradas" (Pals Battalions) reclutados en Gran Bretaña en 1916. ${ }^{117}$

115 Womack, Zapata, p. 182.

116 En la batalla de Torreón, varios participantes recuerdan cómo "los soldados, frenéticos, siguen al general en jefe, contagiados de su valentía”; las brigadas, incluyeron "Madero", [Rosalio] Hernández”, y "Villa”, entre otras. González Garza, Ramos Escobar y Pérez Rul, La batalla de Torreón, pp. 6 y 15. Una excepción fue la Brigada Contreras -llevaba el nombre del caudillo lagunero Calixto Contreras- que se conocía, como La Brigada Carreras, debido a su tendencia de ausentarse cuando la batalla se volvía más intensa. KATz, Life and Times of Pancho Villa, p. 296, citando a Manuel Banda, quizá una fuente no muy fiable.

117 Los llamados pals batallions (batallones de los camaradas) fueron cuerpos de voluntarios reclutados en Gran Bretaña en 1914-1915 entre grupos particulares de la sociedad civil: por ejemplo, vecinos de una ciudad, empleados de una industria (banqueros, tranviarios) y hasta depor- 
En términos logísticos, las campañas dependieron crucialmente de la red ferroviaria para mover y abastecer a las tropas. Ejércitos de este tamaño no podían vivir del campo, como las gavillas de guerrilleros; por lo tanto, aumentó el número de soldaderas (en 1910-1911 apenas existían). Mientras que la revolución maderista de 1910-1911 involucró hombres montados, la de 1913-1914 fue una revolución ferrocarrilera y, en cierto sentido, una revolución de familia. Los nuevos reclutas, además, incluían a jóvenes de 10,12 o 14 años, como el trompetista que ayudó a Obregón a ganar la batalla de Celaya en abril de 1915. ${ }^{118}$ Con la mejor organización y el uso de carros sanitarios parece probable que la mortalidad (relativa) haya disminuido, es decir, los heridos no murieron con tanta regularidad. ${ }^{119}$ Los jefes ahora entendían el valor de las defensas aunque fueran improvisadas, como trincheras y loberas; $\mathrm{o}$

tistas (boxeadores, futbolistas) o hinchas de un club deportivo, como West Ham United. Supuestamente, sus lazos de solidaridad civil subyacerían su moral militar. Sufrieron enormes bajas y, en 1916, la introducción de la conscripción (reclutamiento obligatorio) puso fin a este fenómeno. En contraste, la lucha en México, siendo una revolución sociopolítica, también produjo nombres, digamos, históricos e ideológicos como liberal, Juárez, Zaragoza o los célebres Batallones Rojos.

118 Obregón, Ocho mil kilómetros en campaña, t. II, p. 536. Véase también DAvis, Experiences and Observations, pp. 172-173, que recuerda soldados niños "tantos meros chamacos en uniforme" ("so many mere boys in uniform") entre 8 y 10 años. En Europa hubo reclutas jóvenes, de ahí el llamado kindermord ("matanza de los inocentes") en la batalla de Langemarck (octubre de 1914); aunque estos "inocentes" eran estudiantes alemanes de 18 y más años. STEvenson, 1914-1918, pp. 76-77; después, sí hubo reclutamiento (ilegal) de jóvenes de 16 años, pero jamás - que yo sepa - de niños de 10 o 12 años como en México.

119 Reed se refiere al “excelente tren médico" que Villa tenía en Torreón. ReEd, Insurgent Mexico, p. 23; véase también KATZ, Life and Times of Pancho Villa, p. 292. 
utilizaban defensas existentes como lo hizo Obregón con los canales de riego en Celaya, o los zapatistas cuando se aprovecharon del canal de desagüe en el Distrito Federal. ${ }^{120}$ Obregón, el más brillante y estudioso de los generales, se mantuvo al corriente de los sucesos militares en Europa: por ejemplo, el uso del alambre de púas, que no faltaba en las praderas del norte de México. ${ }^{121}$ En muchos aspectos, la guerra en México se parecía a la de Europa; la diferencia principal (en 1913-1914)

120 Obregón, Ocho mil kilómetros en campaña, con frecuencia menciona el uso de loberas (en inglés foxholes), es decir, pequeños huecos, improvisados, que permitían a un solo soldado tenderse y disparar con cierta protección: por ejemplo, t. I, pp. 22, 167, 171, 209; véase también González Garza, Ramos Escobar y Pérez Rul, La batalla de Torreón, p. 23 y Thord-Grey, Gringo Rebel, p. 249, que menciona "trincheras primitivas" ("crude trenches") utilizadas por los federales en su (fallida) defensa de la ciudad de Tepic y, p. 91, enfatiza el gran interés que tenía Obregón en las tácticas militares europeas. Aunque hubo sistemas de trincheras más extensos -al estilo del Frente Occidental europeo- como en El Ébano, estos servían solamente i) en batallas prolongadas (dos meses y medio en el caso de El Ébano) y ii) en suelo margoso. Cuando se trata de conflictos breves, en tierras rocosas (como muchos en el norte de México, por ejemplo), las trincheras no tenían sentido. Claro, el uso de "trincheras" ya existentes, como el desagüe de la ciudad de México o los canales de riego alrededor de Celaya, fue otra cosa. Katz, The Life and Times of Pancho Villa, p. 488. La (relativa) ausencia de trincheras explica otra "ausencia”, comparada con la guerra europea: los soldados mexicanos nunca, que yo sepa, utilizaron cascos de acero, prefiriendo el "sombrero tejano" del norte, o los anchos sombreros tradicionales de los surianos; aparte del calor (y del costo), el casco de acero se volvió clave en conflictos donde la cabeza fue el blanco principal, es decir, en las trincheras del frente occidental europeo, pero no en las batallas más breves y móviles de México.

121 Sobre el uso de alambre de púas, tanto en las batallas del Bajío como en la defensa de puertos fronterizos como Naco y Agua Prieta y de la capital sonorense, Hermosillo, véase KaTz, The Life and Times of Pancho Villa, pp. 497, 526 y 531. 
fue que los revolucionarios gozaron de mucho mejor moral, basada en lealtades ideológicas, personales, y locales/regionales. En Europa, la moral, afianzada por sentimientos patrióticos, dinásticos y, otra vez, locales/regionales, no se diferenció tanto entre los ejércitos, al menos al inicio. En consecuencia, no vemos, sino hasta mucho más tarde, las deserciones masivas que afectaron al ejército huertista, sobre todo en $1914 .{ }^{122}$

Esta consideración psicológica provoca otra hipótesis que tiene relevancia tanto para la Revolución como para la guerra europea: la noción de la caballerosidad entre los combatientes. A veces se dice que las guerras civiles son más brutales que las internacionales. Esto me parece falso (como regla general). Pensemos en el frente oriental durante la segunda guerra mundial, o la guerra del Pacífico. En cuanto a las guerras civiles, creo que depende de cuándo y dónde. La revolución mexicana, no obstante su gran mortandad, que ya he enfatizado, fue menos bárbara, por ejemplo, que la Guerra Civil Española (en términos de matanzas de civiles y prisioneros, y de curas). Claro, el ejército federal cometió muchos abusos en contra de la población civil en sus campañas de contrainsurgencia, particularmente en Morelos (la reconcentración, la destrucción de viviendas y cosechas, los fusilamientos arbitrarios y ejemplares). Tácticas parecidas se vieron otra vez cuando los carrancistas trataron de imponer su autoridad en Morelos después de 1915. ${ }^{123}$ Como mencio-

${ }^{122}$ El mayor colapso moral ocurrió en Rusia en 1917; antes hubo deserciones en los ejércitos italianos y austro-húngaros, pero no en gran escala; y los célebres motines franceses de 1917 fueron excepcionales. FERGuson, The Pity of War, pp. 344-345.

123 Womack, Zapata, cap. 9; Horcasitas, De Porfirio Díaz a Zapata, cap. 16. 
né, la guerra asimétrica suele provocar estas tácticas, típicas de contextos coloniales. ${ }^{124}$

En contraste, la guerra convencional, simétrica, en México a veces fue conducida con cierta caballerosidad. Eso no quiere decir honrar la Convención de La Haya, como Madero había prometido a principios de la Revolución. ${ }^{125}$ Ya lo mencioné: como práctica regular, los oficiales federales fueron pasados por las armas. Pero los fusilamientos fueron llevados a cabo con cierta cortesía: al preso le dieron un cigarro y o un trago de licor, además de preguntarle por su último deseo (así fue como Cheché Campos pidió: “que me echen tres dedos y me toquen 'El abandonado'”, mientras que el general Pantoja solicitó al pelotón que dispararan derecho y no dañaran su maravilloso sombrero plateado. Con una muestra tanto de valentía como de "matriotismo" - el amor a la patria chica, en palabras de Luis González - un capitán llamó al general enemigo para atestiguar su ejecución, no porque quisiera implorar un indulto, sino porque "quería que viera cómo saben morir los de Sonora”). ${ }^{126}$ En otro caso, un viejo oficial federal, preso por los revolucionarios, escapó del paredón

124 Las campañas de Huerta en Morelos, como otras campañas en las que él había participado durante el porfiriato contra los yaquis y los mayos, se parecen mucho a guerras cuasi coloniales, con fuertes rasgos racistas; el hecho que los soldados rasos federales también fueran indios o mestizos, al mando de oficiales generalmente más blancos que ellos, refuerza y no descalifica la comparación, si se toma en cuenta la formación de los ejércitos coloniales, por ejemplo ingleses y franceses.

125 Ross, Francisco I. Madero, p. 116. En contraste, para Pancho Villa la idea de "las reglas de la guerra" fue una novedad misteriosa. REED, Insurgent Mexico, pp. 132-133.

126 O"Hea, Reminiscences of the Mexican Revolution, p. 109; Alfaro Siqueiros, Me llamaban el coronelazo, p. 156 y el autor agrega: “esto sí es auténtico. Naturalmente, en mis relatos había la apoteosis de la ver- 
porque ellos se enteraron de su servicio patriótico durante la guerra con Francia en la década de 1860.

Esta caballerosidad llegó al colmo en la guerra de los vencedores en 1915, cuando los revolucionarios se pelearon entre sí. Reconocieron que unos pocos meses antes habían sido compañeros de armas. La guerra fue reñida y costosa, pero raras veces degeneró en tormenta, sadismo o matanzas gratuitas. No hay - que yo sepa- reportes de prisioneros torturados para sacar información; tampoco, como mencioné, hubo campos de concentración. Existía cierto respeto recíproco entre los ejércitos (otra vez, vemos un claro paralelo con el Frente Occidental). Esta actitud duró, en cierta medida, durante los años veinte, al menos entre los revolucionarios. Calles podía ser brutal y arbitrario (por ejemplo, la masacre de Huitzilac), pero cuando Cárdenas, lesionado, fue tomado preso por Enrique Estrada en 1923-1924, fue tratado con mucha cortesía; ${ }^{127}$ y el propio Cárdenas trató a Calles, su antiguo patrón, con respeto cuando lo desterró en 1936. Dicen también que lloró cuando Cedillo, habiéndose sublevado, murió en 1939. En contraste, la Guerra Cristera fue librada con mucho odio y poco respeto mutuo: hubo masacres, linchamientos, asesinatos de civiles; mientras que la violencia "micropolítica" de la misma década, de agraristas contra terratenientes, y entre sindicatos rivales en las ciudades textileras, fue brutal, y a veces sádica, por ejemplo, el

dad"; Mendoza Vargas, Gotitas de placer y chubascos de amargura, pp. 90-91.

127 "Debemos proseguir la guerra como gente civilizada y no como salvajes", dijo Estrada (supuestamente); y ordenó a Rafael Buelna "tratar a los prisioneros como viejos camaradas", lo que sí ocurrió en el caso de Cárdenas. Dulles, Yesterday in Mexico, pp. 241-242. 
asesinato de Primo Tapia. ${ }^{128}$ La razón parece clara: la guerra de los ganadores fue una lucha militar, una suerte de violencia "macropolítica", entre ejércitos convencionales en búsca del poder nacional; las escaramuzas "micropolíticas" fueron conflictos locales, políticos, a veces de clase, en donde el terror, la intimidación y la extracción de información fueron clave. Esta fue una "guerra sucia”, que sugiere paralelos con los años setenta y ochenta; las batallas de la Revolución, no obstante su alta mortalidad, formaron parte de una guerra en cierto sentido más limpia.

Fue durante la guerra de los ganadores en 1915 que la revolución mexicana se pareció más a lo que estaba pasando en Europa. Sin entrar en la espinosa cuestión del porqué del conflicto entre Villa y Carranza, su significado militar fue que como en Europa, involucró a ejércitos muy semejantes en cuanto a su organización, formación social, armamento y moral. Los villistas, sobre todo si incluimos a sus aliados, tibios zapatistas, y otras fuerzas nominalmente villistas, tuvieron la ventaja en número; pero esta ventaja se redujo por la decisión de Villa de comprometerse en diferentes campañas (Jalisco, el noreste, Tampico). Las batallas clave tuvieron lugar en el Bajío, entre abril y julio de 1915, cuando Obregón, con buena lógica clausewitziana, decidió enfrentarse a Villa, obligándolo a pelear, con la idea de eliminarlo a él y a la División del Norte como rivales por el poder nacional. Las batallas de 1915 se parecen mucho a las que estaban ocurriendo en Europa al mismo tiempo. Claro, fue una campaña mucho más móvil que el estático frente occidental; pero el frente oriental entre Rusia, Alemania y Austria también fue una

${ }^{128}$ Friedrich, Agrarian Revolt in a Mexican Village, pp. 129-130. 
guerra de mucha movilidad; mientras que el frente occidental comenzó en 1914 y terminó en 1918 con grandes avances y retiros. En México, ambos ejércitos, gozando de alta moral, pensaron que podían ganar; de hecho, los villista probablemente fueron demasiado optimistas ya que la mayoría de los observadores neutrales previeron un triunfo del Centauro del Norte y su siempre victoriosa División del Norte. Pero en 1913-1914 Villa había triunfado contra un ejército (federal) de renuentes conscriptos y a veces había triunfado no obstante sus tácticas cuestionables. ${ }^{129}$ En 1915 Villa se enfrentó a un general experimentado e inteligente y también invicto, que tenía un ejército bien preparado, con un fuerte núcleo sonorense. Tenía también los nuevos batallones rojos, cuerpos de obreros en uniforme, recientemente reclutados. Aunque no creo que ellos determinaran el resultado de las batallas, mostraron que en México, como en Europa, civiles podían ser incorporados en los ejércitos masivos y adaptarse con éxitos a la disciplina de la infantería mecanizada - cosa que los prusianos habían demostrado en 1870 y que todos los beligerantes europeos pondrían en práctica después de 1914.

Aunque el atrevido avance de Obregón hacia el centro del poder villista fue una estrategia agresiva, sus tácticas fueron mucho más defensivas, conforme a la lógica militar de la guerra europea. En Celaya se aprovechó de los canales para atrincherar su infantería, invitando a la célebre caballería villista a atacar, lo que hizo repetidamente y con un enorme costo. El asunto clave para Obregón fue mantener su línea de

129 Por ejemplo, en Tierra Blanca a fines de 1913, cuando Villa “cometió todo error posible pero salió victorioso”. Thord-Grey, Gringo Rebel, p. 53. 
abastecimiento al puerto de Veracruz, potencialmente vulnerable a un ataque zapatista. Pero no hubo ningún ataque serio y los comandantes carrancistas encargados de los trenes fueron los héroes del momento. Aunque a veces faltó parque, nunca perjudicó la tenaz resistencia de los carrancistas. Por otro lado, los ataques villistas, pródigos en su uso de municiones, tampoco fracasaron debido a una falta de parque (de hecho, después de la batalla los carrancistas adquirieron una cantidad abandonada por los villistas). Por tanto, no me convence la tesis de John Hart de que los carrancistas ganaron gracias a los armamentos que los estadounidense les habían regalado en Veracruz, y que les permitieron derrotar a un enemigo que carecía de armas y parque. Villa perdió en virtud de sus erróneas tácticas que muestran su falta de conocimiento de la primera regla de la guerra de ese entonces: la superioridad de una defensa bien atrincherada contra una ofensiva de caballería tradicional. ${ }^{130}$

Celaya no determinó el resultado de la guerra, pero hizo posible un triunfo carrancista, lo que volvió una probabilidad con la mayor batalla de Trinidad/León. Aunque el terreno era menos favorable a los carrancistas que en Celaya, la batalla siguió un formato parecido, y fue seguida por la última gran derrota de Villa en Aguascalientes. Ninguna de estas batallas resultó tan prolongada ni costosa como los grandes com-

130 Conforme ReEd, Insurgent Mexico, p. 130-131, Villa desdeñó la organización formal militar; mostró, dice Reed, una indiferencia "napoleónica" del "cálculo trigonométrico de la trayectorias de los proyectiles" y cosas por el estilo; que, sin duda, fuera una debilidad por parte de Villa, pero de ninguna manera un rasgo "napoleónico", ya que Napoleón era oficial artillero que entendía muy bien estas cosas y gracias a eso ganaba sus batallas. 
bates del frente occidental (del Marne, del Somme, Verdún, Passchendaele). En los grandes espacios abiertos de México nunca se daría una larga guerra basada en las trincheras (aun admitiendo que hubiera recursos económicos suficientes para mantenerla). Pero las batallas del Bajío sí se parecían al frente oriental, con campañas de más movilidad, en las que la caballería todavía tenía un papel, pero no en la forma de impetuosas cargas contra posiciones defensivas.

En la batalla del Ébano, México sí experimentó un conflicto más característico del frente occidental, cuando los villistas de Tomás Urbina repetidamente atacaron una estrecha línea de trincheras que protegía al crucial puerto de Tampico. Los carrancistas, bajo el general Jacinto Treviño (soldado profesional), defendieron una posición entre ríos y pantanos, utilizando ametralladoras, reflectores eléctricos, alambre de púas, e incluso unas pantallas de lámina para protegerse del sol. ${ }^{131}$

131 Sobre la batalla de El Ébano, véanse Barragán Rodríguez, Historia del ejército y revolución constitucionalista, t. 2, pp. 302-307, y GoNZÁlEZ, Contra Villa, pp. 222-224, ambas, vale mencionar, fuentes carrancistas, igual que Gómez Ledesma, "La batalla del Ébano", en https:// es.facebook.com/permalink.php?story_fbid $=182156421873584 \& \mathrm{id}=1$ 63099253779301, consultado el 29 de diciembre de 2013, que depende de Barragán Rodríguez). Durante la batalla, los aviones carrancistas lanzaron bombas de hasta $7 \mathrm{~kg}$ sobre los atacantes villistas y consiguieron información sobre las disposiciones del enemigo. No fue el primer uso del poder aéreo en la Revolución: los revolucionarios sonorenses habían utilizado aviones, de la misma manera, en sus campañas contra los federales en 1913, utilizándolos, sin mucho éxito, contra las trincheras huertistas en Guaymas, los cañoneros federales en la costa de Topolobampo, y el puerto de Mazatlán; este último ataque provocando al almirante estadounidense Howard a protestar formalmente contra "esta manera de hacer la guerra". KNight, The Mexican Revolution, t. 2, p. 148. En ocasiones se dice que este fue el primer uso de la fuerza aérea -aparte de gaviotas y globos- en la guerra: por ejemplo, Cumberland, The Mexican Revolu- 
Los aviones entraron en combate (no por primera vez en la Revolución), y si sus bombardeos resultaron inútiles, podían conseguir información sobre las disposiciones del enemigo y, quizá, alcanzar cierto impacto psicológico. Los villistas también construyeron trincheras, a veces tan cerca de las de sus enemigos que los soldados podían intercambiar gritos e insultos; en un momento, hubo un cortés intercambio de carne (que tenían los carrancistas) por tequila (de los villistas), otro incidente que sugiere no solamente la caballerosidad, sino también la fraternidad que ocurría en el frente occidental, como el célebre partido de futbol entre alemanes e ingleses el día de Navidad de 1914, que ganaron los alemanes. Pero la táctica preferida de los villistas fue la carga de caballería y, otra vez, los villistas se estrellaron contra las trincheras, sufriendo grandes pérdidas, hasta que Villa, que necesitó refuerzos en el Bajío, ordenó un cese a la campaña. Había durado dos meses y medio. Y, la defensa del Ébano no fue única. Guarniciones carrancistas, utilizando las mismas tácticas, exitosamente resistieron ofensivas villistas (de mucho mayor número) en Matamoros, Naco y Agua Prieta.

Mi conclusión sería que la guerra de los ganadores no tuvo un resultado predestinado: como la batalla de Waterloo, en palabras de Wellington, Celaya y León fueron "conflictos muy nivelados". El triunfo carrancista, a mi modo de ver, no dependió de ventajas en cuanto a recursos (humanos o materiales); tampoco fue producto de la ayuda estadounidense; aun en la batalla de Aguascalientes, los villistas estaban bien

tion, p. 123; es casi cierto, pero parece que el uso de aviones por parte de los italianos en la guerra contra los turcos en Libia (1911), lo precedió por dos años. Addington, The Patterns of War, p. 93. 
pertrechados. Más bien, dependía de una buena y experimentada organización logística que el ejército mantuvo durante tres meses de conflicto por medio de cada vez más largas líneas de comunicación, aunada a las inteligentes tácticas de Obregón. Y, cuando Obregón fue lesionado y casi muerto, sus oficiales sabían cómo llevar a cabo el plan de batalla ya iniciado. En contraste, Villa, como Urbina en El Ébano, persistió en las tácticas que habían sido exitosas contra los conscriptos federales en 1913-1914, pero que resultaron suicidas contra un general y un ejército de origen revolucionario. La causalidad, entonces, fue militar, y como los resultados fueron clave, las batallas determinaron quiénes gobernarían México durante décadas, lo que me sugiere que la historia militar es algo que debemos tomar muy en serio.

\section{IV}

Por último quiero considerar consecuencias de más larga duración de la guerra total. Por supuesto, como un movimiento político, la revolución mexicana, para triunfar, tuvo que granjearse el apoyo popular haciendo promesas (en cuanto a la reforma laboral y agraria, por ejemplo). En Europa, aunque la guerra fue internacional, también hubo promesas y compromisos (ya sea explícitos o implícitos): en Gran Bretaña, un sufragio mayor (incluyendo a las mujeres) y lo que el primer ministro Lloyd George - liberal progresivo y algo populista - llamó "hogares apropiados para los héroes" (homes fit for heroes). Como muchas promesas, esta no fue cumplida; cuando la guerra terminó y la reconstrucción comenzó, los compromisos bélicos se esfumaron y, en el caso británico, fueron obstaculizados por la crasa políti- 
ca del entonces ministro de Hacienda, Winston Churchill, para regresar al patrón oro con una libra sobrevaluada. El gobierno sí dio el sufragio a las mujeres, en parte por sus servicios durante la guerra, pero esto no costó nada al erario. Al otro extremo, la guerra hizo posible la conquista de poder por los bolcheviques en Rusia, pero no queda claro si consecuentes reformas radicales fueron deseadas por la mayoría de la población o fueron producto de un pacto social forjado durante la guerra. Por tanto, mientras que la movilización masiva de la guerra europea sí provocó demandas, promesas y expectativas político sociales, la tendencia en los años veinte fue lo que el presidente Coolidge llamó "un regreso a la normalidad" (a return to normalcy), que quiere decir poca o nada reforma. El verdadero pacto social, forjado en la encrucijada de una guerra total, tuvo que esperar a la segunda guerra mundial y la creación del Estado de bienestar en los años cuarenta. ${ }^{132}$

En México, la Revolución sí estableció una suerte de pacto social, producto de la guerra y de las necesidades del flamante Estado constitucionalista/sonorense. Por sus sacrificios, los mexicanos, especialmente los que habían tomado las armas en contra del antiguo régimen, merecieron sus premios. Este principio de reciprocidad (movilización armada que conlleva beneficios políticos) no fue nuevo; se había visto, por

132 Un factor clave fue la gran depresión de 1930, que reveló la bancarrota de la política económica en muchos países, provocando así un pensamiento "paradigmático", que la experiencia de la (segunda) guerra, es decir, un nuevo pacto social, aunado a experimentos en planeación macroeconómica se convirtió en el nuevo proyecto del estado de bienestar y políticas keynesianas después de 1945. 
ejemplo, en la historia de los serranos oaxaqueños en el siglo XIX. ${ }^{133}$ Pero con la Revolución el pacto fue de mayor envergadura, siendo nacional, radical y duradero. Obregón fue un protagonista elocuente - a veces demagógico - de esta filosofía: los que habían ganado la Revolución merecieron sus premios; los que se habían quedado al margen del conflicto, o peor aún, habían resistido a la Revolución, merecieron nada. ${ }^{134}$ La versión de Obregón fue "de arriba abajo"; un esfuerzo para representar la Revolución y forjar la legitimidad del nuevo régimen. Pero también hubo muchas versiones "de abajo arriba". Individuos buscando beneficios - chambas, promociones, protección - engalanaron sus peticiones haciendo referencia a sus servicios en pro de la Revolución. Veteranos invocaron sus sacrificios y hasta sus cicatrices. Sus líderes prestaban atención: caudillos locales/regionales, como Cedillo, Gabriel Barrios, e incluso Villa, después de su retiro a Canutillo, conforme se transformaron de caudillos en caciques, mantuvieron y protegieron a sus antiguos seguidores, a veces dándoles tierras en la patria chica común. ${ }^{135}$ Por supuesto, este proceso involucró algo de ficción, conforme los solicitantes exageraron o fabricaron sus carreras revolucionarias. ${ }^{136} \mathrm{La}$ investigación de la realidad de los anteceden-

\footnotetext{
${ }^{133}$ McNamara, The Sons of the Sierra, pp. 185-186.

134 KNight, Mexican Revolution, t. 2, p. 255.

135 Ankerson, Agrarian Warlord, cap. 6; Brewster, Militarism, Ethnicity and Politics; Meyer, Pastor, Sepúlveda y Souza, "La vida con Villa en la Hacienda de Canutillo", pp. 170-183.

${ }^{136}$ Un buen ejemplo ficticio de estas ficciones sería el general Xicontencatl Robespierre Cebollino, cuyo nombre, impecablemente revolucionario, disfraza un pasado huertista y porfirista, lo que comparte con otros personajes oportunistas de la misma novela de Azuela, Domitilo quiere ser diputado.
} 
tes "revolucionarios" (o reaccionarios) ocupó mucho tiempo en el Congreso Constituyente de Querétaro, y durante décadas, la cuestión de dudosos antecedentes políticos afectó a las carreras políticas. ${ }^{137}$

Más importante, las demandas colectivas no individuales podían avanzar bajo la rúbrica de "servicios a la Revolución": por sindicatos buscando reconocimiento y, el caso clásico, por comunidades solicitando ejidos, lo que podemos llamar, citando a Lloyd George, "ejidos apropiados para los héroes". Estas solicitudes muchas veces tuvieron éxito, no necesariamente debido a la justicia del reclamo, sino porque las comunidades en cuestión si tenían antecedentes revolucionarios, probablemente tenían también cierta organización colectiva, líderes experimentados, acceso a las armas y relaciones clientelares con poderosos caudillos/caciques. ${ }^{138}$ Invirtiendo a Clausewitz, se puede decir que, en los años veinte y treinta, la política fue la continuación de la guerra (revolucionaria) por otros medios. No es una coincidencia que la geografía de la reforma agraria temprana en los años veinte haya reflejado la geografía de la insurgencia armada en la década anterior. ${ }^{139}$

137 Por ejemplo, cuando Adolfo Ruiz Cortines se postuló para presidente tenía que contrarrestar la acusación de haber funcionado como oficial en el puerto de Veracruz durante la ocupación estadounidense en 1914: Navarro, Political Intelligence and the Creation of Modern Mexico), p. 222.

138 Brading (coord.), Caudillo and Peasant, inauguró una importante ola de investigación de los caudillos y caciques de la Revolución, estudios que incluyen, entre otros, los de Martínez Assad (coord.), Estadistas, caudillos y caciques y Knight y PANsters (coords.), Caciquismo in Twentieth-Century Mexico.

139 Knight, “Tierra y sociedad en el México revolucionario, t. 2, pp. 33-34. 
En este proceso, dos aspectos relacionados son claros y sugieren otros paralelos con Europa: el papel de los veteranos y la continua incidencia de la violencia. En Europa, millones de exsoldados fueron licenciados en 1917-1919. En México, hubo decenas de miles. Por supuesto, muchos quedaron como soldados, pero el padrón del ejército federal disminuyó y fue renovado por las reformas de Amaro en los años veinte. De 250000 en 1916, el padrón bajó a 53000 diez años después. ${ }^{140}$ Pero el ejército no fue el único cuerpo armado. Sobre todo en sus últimos años (1915-1920) la Revolución había visto una proliferación de defensas sociales, grupos de vigilantes comprometidos a defender sus comunidades contra bandidos y rebeldes de fuera (que al mismo tiempo forjaban sus propias carreras políticas). ${ }^{141}$ Muchos prominentes políticos emergieron dentro de los rangos de las defensas sociales, por ejemplo, Jesús Almeida e Ignacio Enríquez de Chihuahua. ${ }^{142} \mathrm{Al}$ mismo tiempo, el movimiento agrarista formó, como tenía que hacerlo, su ala paramilitar. Solicitar un ejido a veces fue un proceso muy peligroso que necesitó luchadores dispuestos

140 Ramírez Rancaño, "Una discusión sobre el tamaño del ejército mexicano", p. 45. La cifra para 1916, tomada, como parece, de RicHMond, Venustiano Carranza"s Nationalist Struggle, p. 156, que no cita ninguna fuente correspondiente, me parece demasiada alta. Pero las cifras sugieren correctamente la marcada caída en el padrón militar durante la década 1916-1926; después de 1926 hubo un leve aumento, debido a la rebelión cristera. Loyo CAMACHO, Joaquín Amaro ofrece un buen análisis del proceso de reforma y adelgazamiento militar.

141 Knight, The Mexican Revolution, t. 2, pp. 83-4, 437-438.

142 Gruening, Mexico and its Heritage, pp. 410-411, ofrece una versión contemporánea; Wasserman, Persistent, pp. 17, 45, 48, 96, un análisis histórico. 
a pelear por la causa y proteger a sus compañeros. ${ }^{143}$ Fuertes cacicazgos, como el de Ernesto Prado, de los Once Pueblos de Michoacán, fue así establecido. ${ }^{144}$ Los terratenientes también recurrieron a la violencia informal para proteger sus intereses contra la amenaza agrarista: quijotesca y desastrosamente en el caso de Rosalie Evans; más despiadada y eficaz con los Noriega de Cantabria, o Manuel Parra de Almolonga. ${ }^{145} \mathrm{Al}$ principio, el flamante Estado revolucionario tenía que tolerar y a veces depender de estas fuerzas paramilitares, aun así el ejército federal las resintió. Durante la Cristiada, los irregulares agraristas, como los veteranos de Cedillo, desempeñaron un papel clave, y a veces fueron más eficaces que los federales (que en los años veinte adquirieron algunos de los vicios del antiguo ejército porfirista: corrupción, padrones inflados y altas tasas de deserción). ${ }^{146}$ Con el tiempo, las fuerzas irregulares disminuyeron, pero nunca desaparecieron y, en los años treinta, la flamante CTM estableció su propia milicia, provocando también la oposición del ejército regular.

La continuada violencia de los años veinte y treinta, lo que en otra parte he llamado violencia micropolítica, ${ }^{147}$ reflejó el hecho de que la sociedad mexicana había emergido de la revolución armada hasta los dientes. Las memorias de Gonzalo N. Santos no son de ninguna manera típicas, pero el culto de las armas evidente en sus páginas no fue una mera

143 Friedrich, Agrarian Revolt in a Mexican Village, y Craig, The First Agraristas, son buenos ejemplos.

144 Calderón, “Caciquismo y cardenismo, pp. 134-139.

145 Henderson, The Worm in the Wheat; Friedrich, Agrarian Revolt in a Mexican Village; SANTOYo, La Mano Negra.

146 Meyer, The Cristero Rebellion, pp. 56, 104, 106-108, 160-162.

147 Knight, "War, Violence and Homicide in Modern Mexico". 
idiosincrasia individual, sino más bien una característica de la época. ${ }^{148}$ Había habido una masiva importación de armas, y toda una generación de jóvenes se habían adiestrado en su uso (tanto armas de fuego como armas blancas); al mismo tiempo, habían cruzado el umbral psicológico que divide los "pacíficos" de los "militares", se habían acostumbrado a la violencia, incluso, en ciertos casos, al asesinato. A algunos les gustaba. La violencia cotidiana no era nada nuevo en México: la paz porfiriana fue, en cierta medida, un mito y tuvo que ver principalmente con la macropolítica; pero la violencia política porfiriana fue en general autoritaria, "arriba/abajo”, mientras que, después de la Revolución, se volvió más democrática, “abajo/arriba”. Al menos, la violencia después de 1910 fue una calle de dos sentidos. Y esto reflejó lo que Richard Cobb escribió (sobre la revolución francesa) hace años: "parece probable que siempre costará bastante tiempo empujar al pueblo fuera de una situación revolucionaria cuando ya no se necesita". ${ }^{149}$

Hubo fenómenos parecidos en Europa después de 1918: los hombres (ya que fue un fenómeno esencialmente masculino), adiestrados durante años en el uso de las armas y las prácticas violentas, no podían regresar fácilmente a sus hogares, fábricas, oficinas o milpas. Por tanto, vemos fenómenos como los Freikorps en Alemania (los precursores del SA nazi), los squadristi italianos, que ayudaron a Mussolini a tomar el poder en 1922, y los llamados Black and Tans (negros y morenos) británicos, que combatieron - a veces brutalmente - a los nacionalistas irlandeses durante la crisis de la pos-

\footnotetext{
148 Santos, Memorias.

149 Совв, The Police and the People, p. 85.
} 
guerra. Todos estos grupos paramilitares fueron nacionalistas y - en cierto sentido - derechistas, mientras que en Rusia, por contraste, los exsoldados zaristas, incluso los oficiales, apoyaron a los bolcheviques y en Turquía los veteranos de guerra se volvieron los arquitectos del nuevo régimen - secular, nacionalista y progresivo - bajo el liderazgo carismático del general Kemal Ataturk, régimen admirado por algunos caudillos mexicanos, como Cedillo. ${ }^{150}$

En Europa, el papel político de los veteranos, aunque se veía a través del espectro ideológico, tendía más hacia la derecha; en México el balance fue diferente, otra vez, porque la guerra total mexicana fue también una revolución social con fuertes rasgos progresistas/radicales. (Una contrafactual: si Huerta hubiera ganado, ¿qué régimen hubiera inaugurado? Probablemente uno medio fascista/militar.) Sin embargo, es interesante ver cómo, conforme el Estado revolucionario se consolidaba en los años veinte y treinta, los veteranos, los que habían militado en las filas del ejército revolucionario, se movieron hacia la derecha. Los "veteranos" se opusieron a la radicalización de la reforma agraria en los treinta. ${ }^{151} \mathrm{La}$ Unión Nacional de Veteranos de la Revolución, aparte de su papel como organización de cabildeo en pro de sus miembros, adoptó posturas políticas cada vez más conservadoras: en contra de Cárdenas y (a fortiori) de Lombardo, y en pro de los viejos caudillos militares, los íconos de la llamada derecha radical de los treinta, como Amaro, Cedillo y Manuel Pérez Treviño. ${ }^{152}$ Nicolás Rodríguez, exveterano villista, encabezó

150 Ankerson, Agrarian Warlord, p. 141.

151 Simpson, The Ejido, pp.126, 439-443.

152 Rath, Myths of Demilitarization, cap. 6. 
los camisas doradas, que se ufanaban se su lealtad al legado del Centauro del Norte, mientras que se vestían y se comportaban al estilo de los fascistas europeos. ${ }^{153}$ En emulación de sus correligionarios europeos, varios grupúsculos de la derecha radical ostentaron un fuerte antisemitismo. Este cambio de dirección de los veteranos hacia la derecha fue producto del paso del tiempo, de su evolución personal de jóvenes rebeldes ( $\mathrm{y}$ a veces pobres) a hombres de mediana edad más gordos y prósperos, y de la radicalización del régimen de Cárdenas. Un factor secundario fue quizá la afición de los veteranos por posturas patrióticas, jerárquicas y militaristas, todas producto de su militancia en el ejército revolucionario; posturas que podían asumir tanto aspectos de derecha, por ejemplo con Cedillo, como izquierdistas, con Cárdenas. Después de todo, valores de esta índole habían apuntalado la Revolución: sin una eficaz jerarquía militar, los revolucionarios nunca hubieran derrotado a Huerta; mientras que un fuerte nacionalismo subyació a la política exterior de Carranza. 20 años después, los mismos valores estuvieron más asociados con la derecha, al lado de Hitler y Mussolini y el corporativismo estatal. Se me ocurre que un ejemplo similar reciente es la carrera política del líder sandinista Daniel Ortega.

En este contexto, hay que mencionar que, no obstante la fuerte polarización política de los años treinta, la lealtad militar/revolucionaria retuvo su poder. Aunque Cedillo rechazó el llamado "comunismo" de Cárdenas, no podía olvidar que había sido cobeligerante en la revolución armada; de la misma manera, Gonzalo N. Santos expresó su respeto y su camara-

153 CAmpbell, La derecha radical en México, pp. 51-55; GoJMAN DE BACKAL, Camisas, escudos y desfiles militares, pp. 230-239. 
dería con el presidente, cuyo radicalismo no compartió. ${ }^{154}$ En estos años, hablaban de un "Franco mexicano" que rescataría al país de la amenaza del comunismo, pero el hecho de que el presidente, supuestamente comunista, fuera un alto oficial del ejército y veterano de la Revolución, cuyo valor como soldado y no su capacidad como general fuera de reproche, le dio una autoridad que ningún civil podía poseer. $\mathrm{Al}$ mismo tiempo, Cárdenas tuvo buena relación con el ejército, tanto con los oficiales como con los soldados rasos. En parte por eso no hubo ninguna revuelta militar al estilo de Franco; la rebelión de Cedillo resultó una llamarada de petate.

Por último, quiero mencionar, como consecuencia de la guerra total, el papel del Estado. Tanto en México como en Europa la prosecución de la guerra total resultó en un Estado que en el caso mexicano controló los ferrocarriles, expropió los bancos, manejó los bienes intervenidos, aplicó nuevos impuestos y aumentó su gasto militar. Es cierto que con la consolidación del nuevo régimen, estos compromisos fueron reducidos. Al contrario de lo que a veces se supone, la Revolución no provocó un aumento notable y permanente en el gasto del Estado: más bien hubo un crecimiento lento y paulatino. ${ }^{155}$ Sí hubo un aumento en el papel regulador del Estado, que la Constitución de 1917 afianzó y legitimó. Los recursos del subsuelo fueron declarados propiedad de la nación, el Estado tuvo el derecho de expropiar la propiedad en pro del bien común; la Iglesia tuvo que subordinarse al Estado; y éste asumió un papel algo más nacionalista en sus relaciones con los intereses y los gobiernos extranjeros. Estas

154 SANTos, Memorias, pp. 279, 349, 382, 444, 489, 510-511.

155 KnIGHt, “The Weight of the State in Modern Mexico”, pp. 217-18. 
políticas no fueron costosas en términos financieros (al contrario, contribuyeron al erario), por tanto no se las puede calibrar por medio del presupuesto estatal (que, repito, no fue de ninguna manera "revolucionado" por la Revolución). Tampoco se puede decir que estas políticas de reglamento fueron sólo producto de la guerra (ya que también respondieron a intereses sociales y proyectos ideológicos). Sin embargo, tanto en México como en Europa, la experiencia de una guerra total, la movilización masiva y la mayor intervención estatal en la economía (en cierto sentido una economía de guerra) estableció precedentes y quizá rompió tabues. La innovación político económica que se veía en México en los años treinta - como, por ejemplo, la política keynesiana avant la lettre de Alberto J. Pani- fue en cierta medida posibilitada por la experiencia heterodoxa de los años de la Revolución. En otras palabras, varios aspectos de la política mexicana en ese entonces - comparada con otros países de América Latina- resultó no solamente de una revolución social y popular, sino también de una guerra total que había movilizado a la población y dotado al gobierno con nuevos poderes - en suma, una experiencia insólita en América Latina en la primera mitad del siglo xx, pero comparable, mutatis mutandi, con lo que pasó en Europa hace un siglo, de 1914 en adelante.

Traducción del autor con la ayuda de Lidia Lozano. 


\section{REFERENCIAS}

Addington, Larry H.

The Patterns of War since the Eighteenth Century, Beckenham, Inglaterra, Croom Helm, 1984.

Aguilar Camín, Héctor

La frontera nómada: Sonora y la Revolución Mexicana, México, Siglo Veintiuno Editores, 1985.

Albert, Bill

South America and the First World War: The Impact of the War on Brazil, Argentina, Peru and Chile, Cambridge, Cambridge University Press, 1988.

Alessio Robles, Miguel

Obregón como militar, México, Cultura, 1935.

Alfaro Siqueiros, David

Me llamaban el coronelazo, México, Grijalbo, 1986.

Ankerson, Dudley

Agrarian Warlord. Saturnino Cedillo and the Mexican Revolution in San Luis Potosi, DeKalb, IL, University of Northern Illinois University Press, 1984.

Aron, Raymond

The Century of Total War, Boston, Beacon Press, 1968.

Azuela, Mariano

Domitilo quiere ser diputado, México, A. Carranza e hijos, 1918.

BARRAgÁN RodrígueZ, Juan

Historia del ejército y de la Revolución constitucionalista, México, Instituto Nacional de Estudios Históricos de la Revolución Mexicana, 1985. 
Beckett, Ian

The Victorians at War, Londres, Hambledon, 2006.

Berumen Campos, Arturo

"Entrevista con un villista sobreviviente", en Alegatos, 75 (mayo-ago. 2010).

BOghaRdt, Thomas

The Zimmermann Telegram. Intelligence, Diplomacy and America's Entry into World War I, Annapolis, Naval Institute Press, 2012.

Brading, David A. (coord.)

Caudillo and Peasant in the Mexican Revolution, Cambridge, Cambridge University Press, 1980.

BREWER, John

The Sinews of Power: War, Money and the English State, 16881783, Nueva York, Alfred A. Knopf, 1989.

Brewster, Keith

Militarism, Ethnicity and Politics in the Sierra Norte de Puebla, 1917-1930, Tucson, University of Arizona Press, 2003.

BRown, Jonathan C.

Oil and Revolution in Mexico, Berkeley, University of California Press, 1993.

Calderón, Marco Antonio

"Caciquismo y cardenismo in the Sierra P'urbépecha, Michoacán”, en Knight y Pansters (coords.), 2005, pp. 134-139.

Campbell, Hugh G.

La derecha radical en México, 1929-1949, México, Secretaría de Educación Pública, 1976. 
CÁrdenas, Elisa y Annick Lempérière (coords.)

Una ausencia que convoca. Homenaje a François-Xavier Guerra, Guadalajara, Universidad de Guadalajara, 2007.

Centeno, Miguel Ángel

Blood and Debt: War and the Nation-State in Latin America, University Park, Pennylvania State University Press, 2002.

Совв, Richard

The Police and the People. French Popular Protest, 1789-1820, Oxford, The Clarendon Press, 1970.

Cohen, Edward E.

The Athenian Nation, Princeton, Princeton University Press, 2000.

Coupland, R. (coord.)

The War Speeches of William Pitt the Younger, Oxford, The Clarendon Press, 1915.

Craig, Ann L.

The First Agraristas. An Oral History of a Mexican Agrarian Movement, Berkeley, University of California Press, 1983.

Cumberland, Charles C.

The Mexican Revolution. The Constitutionalist Years, Austin, University of Texas Press, 1972.

Davis, Will B.

Experiences and Observations of an American Consular Officer during the Recent Mexican Revolutions, Chula Vista, Cal., publicado por el autor, 1920.

Dehne, Philip A.

On the Far Western Front: Britain"s First World War in South America, Manchester, Manchester University Press, 2009. 
Dixon, Norman F.

On The Psychology of Military Incompetence, Londres, Jonathan Cape, 1976.

Dulles, J. W. F.

Yesterday in Mexico. A Chronicle of the Revolution, 19191936, Austin, University of Texas Press, 1961.

Dunkerley, James (coord.)

Studies in the Formation of the Nation State in Latin America, Londres, ILAs, 2002.

Esdaile, Charles

Napoleon's Wars, Londres, Penguin, 2008.

Fallaw, Ben y Terry Rugeley

"Redrafting History: The Challenges of Scholarship on the Mexican Military Experience", en FALlaw y Rugeley (coords.), Forced Marches: Soldiers and Military Caciques in Modern Mexico, Tucson, University of Arizona Press, 2012, pp. 7-8.

Farrar-Hockley, A. H.

The Somme, Londres, Pan Books, 1966.

FERguson, Niall

The Pity of War, 1914-1918, Londres, Penguin, 1999.

Ferro, Marc

The Great War 1914-1918, Londres, RKP, 1973.

FRIEDRICH, Paul

Agrarian Revoltin in a Mexican Village, Chicago, University of Chicago, 1997.

Fuentes, Carlos

A New Time for Mexico, Berkeley, University of California Press, 1997. 
Gamio, Manuel

Mexican Immigration to the United States, Nueva York, Arno Press, 1969.

GAT, Avar

War in Human Civilization, Oxford, Oxford University Press, 2006.

Gates, David

Warfare in the Nineteenth Century, Basingstoke, Palgrave, 2001.

Gojman de Backal, Alicia

Camisas, escudos y desfiles militares. Los Dorados y el antisemitismo en México (1934-1940), México, Fondo de Cultura Económica, 2000.

Gómez Ledesma, Arístides

“La batalla del Ébano”, en https://es.facebook.com/permalink.php?story_fbid= $182156421873584 \& \mathrm{id}=1630992537793$ 01, consultado el 29 de dic. 2013.

González, Manuel W.

Contra Villa. Relato de la campaña 1914-1915, México, Botas, 1935.

González Garza, R., P. Ramos Escobar y J. Pérez Rul

La batalla de Torreón, El Paso, Printing Co., s. f. [1914].

Grieb, Kenneth J.

The United States and Huerta, Lincoln, University of $\mathrm{Ne}$ braska Press, 1969.

Gruening, Ernest

Mexico and its Heritage, Londres, Stanley Paul \& Co., 1928.

HART, John Mason

Revolutionary Mexico: The Coming and Process of the Mexican Revolution, Berkeley, University of California Press, 1987. 
Empire and Revolution: Americans in Mexico since the Civil War, Berkeley, University of California Press, 2002.

Henderson, Timothy J.

The Worm in the Wheat. Rosalie Evans and Agrarian Struggle in the Puebla-Tlaxcala Valley of Mexico, 1906-1927, Durham, Duke University Press, 1998.

Herrera Sipriano, Francisco

La Revolución en la Montaña de Guerrero. La lucha zapatista 1910-1918, México, Instituto Nacional de Antropología e Historia, 2009.

Horcasitas, Fernando

De Porfirio Diaz a Zapata. Memoria nábuatl de Milpa Alta, México, Universidad Nacional Autónoma de México, 1974.

Horne, Alistair

The Price of Glory, Harmondsworth, Penguin, 1978.

Howard, Michael

War in European History, Oxford, Oxford University Press, 1976.

Joseph, Gilbert M.

Revolution from Without: Yucatán, Mexico and the United States, 1880-1924, Cambridge, Cambridge University Press, 1982.

Joseph, Gilbert M. y Jürgen Buchenau

Mexico's Once and Future Revolution. Social Upheaval and the Challenge of Rule since the Late Nineteenth Century, Durham, Duke University Press, 2013.

JÜNGER, Ernst

The Storm of Steel, Londres, Penguin, 2004. 
KATZ, Friedrich

The Secret War in Mexico: Europe, The United States and the Mexican Revolution, Chicago, Chicago University Press, 1981.

The Life and Times of Pancho Villa, Stanford, Stanford University Press, 1998.

KeEgan, John

The Face of Battle, Harmondsworth, Penguin, 1978.

Kiernan, V. G.

Colonial Empires and Armies, Thrupp, Inglaterra, Sutton Publishing, 1998.

Knight, Alan

"The Weight of the State in Modern Mexico", en Dunkerley (coord.), 2002, pp. 217-218.

"La Revolución mexicana de François-Xavier Guerra: coincidencias y discrepancias", en CÁrdenas y Lempérière (coords.), 2007, pp. 118-19.

"La Revolución mexicana: ¿burguesa, nacionalista o simplemente una 'gran rebelión'?”, en KNIGHT, 2013, t. 2, pp. 499-565.

“Tierra y sociedad en el México revolucionario: la destrucción de las grandes haciendas", en KNight, 2013, t. 2, pp. 33-34. Repensar la Revolución mexicana, México, El Colegio de México, 2013.

"War, Violence and Homicide in Modern Mexico", en Bulletin of Latin American Research, 32:1 (mar. 2013), pp. 12-48. The Mexican Revolution, Cambridge, Inglaterra Cambridge University, Press, 1986, t. 2.

Knight, Alan y Wil G. Pansters (coords.)

Caciquismo in Twentieth-Century Mexico, Londres, IsA, 2005. 
Kuntz Ficker, Sandra

"The Export Boom of the Mexican Revolution: Characteristics and Contributing Factors", en Journal of Latin American Studies, 36:2 (abr. 2004), pp. 267-296.

LaFrance, David G.

Revolution in Mexico's Heartland: Politics, War and StateBuilding in Puebla, 1913-1920, Lanham, Md., Rowman and Littlefield, 2007.

Langle Ramírez, Arturo

El militarismo de Victoriano Huerta, México, Universidad Nacional Autónoma de México, 1976.

Loyo Camacho, Martha Beatriz

Joaquín Amaro y el proceso de institucionalización del ejército mexicano, 1917-1931, México, Universidad Nacional Autónoma de México, 2003.

Macaulay, Thomas Babington

The Life of Frederick the Great, Nueva York, Hurd and Houghton, 1877.

Martínez Assad, Carlos (coord.)

Estadistas, caudillos y caciques, México, Universidad Nacional Autónoma de México, 1988.

McCAa, Robert

"The Missing Millions: The Demographic Costs of the Mexican Revolution", en Mexican Studies/Estudios Mexicanos, 19:2 (2003), pp. 367-400.

McNamara, Patrick J.

The Sons of the Sierra. Juarrez, Diaz and the People of Ixtlan, Oaxaca, 1855-1920, Chapel Hill, University of North Carolina Press, 2007. 
Mendoza Vargas, Eutiquio

Gotitas de placer y chubascos de amargura. Memorias de la Revolución mexicana en las Huastecas, Xalapa, Universidad Veracruzana, 1998.

Meyer, Jean

The Cristero Rebellion, Cambridge, Cambridge University Press, 1976.

Meyer, Eugenia, María Alba Pastor, Ximena Sepúlveda y María Isabel SouzA

"La vida con Villa en la Hacienda de Canutillo", en Secuencia, 5 (mayo-ago. 1986), pp. 170-183.

Mier y Terán, Marta

"Evolución de la población mexicana, 1895-1970", en ScHMIDT, Wilkie y Esparza (coords.), 1988, pp. 93-102.

Moran, Daniel y Arthur Waldron (eds.)

The People in Arms: Military Myth and National Mobilization since the French Revolution, Cambridge, Cambridge University Press, 2003.

Navarro, Aaron

Political Intelligence and the Creation of Modern Mexico, 1938-1954, University Park, Pennsylvania State University Press, 2010.

Nester, William R.

The First Global War: Britain, France and the Fate of North America, Westport, Praeger, 2000.

Obregón, Álvaro

Ocho mil kilómetros en campaña, México, Consejo Nacional para la Cultura y las Artes, 2008. 
Offer, Avner

The First World War: An Agrarian Interpretation, Oxford, The Clarendon Press, 1989.

O’Hea, Patrick

Reminiscences of the Mexican Revolution, México, Centro Anglo Mexicano del Libro, 1966.

Olivera, Alicia (coord.)

Mipueblo durante la Revolución, México, Instituto Nacional de Antropología e Historia, 2010, t. 1.

PArker, Geoffrey

The Military Revolution, Cambridge, Cambridge University Press, 1996.

PAsztor, Suzanne B.

The Spirit of Hidalgo. The Mexican Revolution in Coabuila, Calgary, University of Calgary Press, 2002.

PÉrez, Esther R., James Kallas y Nina Kallas (coords.)

Those Years of the Revolution, 1910-20: Authentic Bilingual Life Experiences as Told by Veterans of the War, San José, Aztlan Today Publishing Co., 1974.

Pollock, Tom

Battle for Empire. The Very First World War, 1756-1763, Londres, Michael O'Mara Books, 1988.

Portilla, Santiago

Una sociedad en armas. Insurrección antirreeleccionista en México, 1910-1911, México, El Colegio de México, 1995.

Ramírez Rancaño, Mario

"Una discusión sobre el tamaño del ejército mexicano, 18761930", en Estudios de Historia Moderna y Contemporánea de México, 32 (jul.-dic., 2006), pp. 35-71. 
Rath, Thomas

Myths of Demilitarization in Postrevolutionary Mexico, 19201960, Chapel Hill, University of North Carolina Press, 2013.

REED, John

Insurgent Mexico, Nueva York, Simon and Schuster, 1969.

Richmond, Douglas W.

Venustiano Carranza's Nationalist Struggle, 1893-1920, Lincoln, University of Nebraska Press, 1983.

Riguzzi, Paolo

¿Reciprocidad imposible? La politica del comercio entre México y Estados Unidos, 1857-1938, México, Instituto de Investigaciones Dr. José María Luis Mora, El Colegio Mexiquense, 2003.

Rodríguez Kuri, Ariel

Historia del desasosiego. La revolución en la ciudad de México, 1911-1922, México, El Colegio de México, 2010.

Rodríguez Kuri, Ariel y María Eugenia Terrones

"Militarización, guerra y geopolítica: el caso de la ciudad de México en la Revolución”, en Relaciones: Estudios de Historia y Sociedad, 84 (otoño 2000), pp. 177-178.

Ross, Stanley R.

Francisco I. Madero: Apostle of Mexican Democracy, Nueva York, Columbia University Press, 1955.

Rothenberg, Gunther E.

The Napoleonic Wars, Londres, Cassel, 1999.

Salas, Elizabeth

Soldaderas in the Mexican Military: Myth and History, Autin, Texas, University of Texas Press, 1990. 
SAntos, Gonzalo N.

Memorias, México, Grijalbo, 1986.

Santoyo, Antonio

La Mano Negra. Poder regional y Estado en México (Veracruz, 1928-1943), México, Consejo Nacional para la Cultura y las Artes, 1995.

Schmidt, Samuel, James W. Wilkie y Manuela Esparza (coords.)

Estudios cuantitativos sobre la historia de México, México, Universidad Nacional Autónoma de México, 1988.

SCHUler, Friedrich

Mexico between Hitler and Roosevelt. Mexican Foreign Relations in the Age of Lázaro Cárdenas, 1934-1940, Albuquerque, Universty of New Mexico Press, 1998.

SHefField, Gary

The Chief: Douglas Haig and the British Army, Londres, Aurum Press, 2011.

Simpson, Eyler

The Ejido: Mexico's Way Out, Chapel Hill, University of North Carolina Press, 1937.

Smith, Anthony D.

The Ethnic Origins of Nations, Oxford, Blackwell, 1986.

Sмiтh, Robert Freeman

The United States and Revolutionary Nationalism in Mexico, 1916-1934, Chicago, University of Chicago Press, 1972.

Stevenson, David

“The Railway Race before 1914”, en Past and Present, 162:1 (1999), pp. 163-194.

1914-1918. The History of the First World War, Londres, Penguin, 2012. 
STONE, Norman

The Eastern Front, 1914-1917, Londres, Penguin, 1998.

TAYLOR, A. J. P.

War By Timetable: How the First World War Began, Londres, MacDonald, 1969.

TERRAINe, John

Douglas Haig: The Educated Soldier, Londres, Hutchinson, 1963.

Thompson, E. P.

The Making of the English Working Class, Harmondsworth, Penguin, 1968.

THORD-GRAY, Ivor

Gringo Rebel: Mexico 1913-1914, Coral Gables, University of Miami Press, 1960.

Tuchman, Barbara

The Zimmermann Telegram, Londres, MacMillan, 1981.

UlloA, Berta

Historia de la Revolución Mexicana, periodo 1914-1917: la encrucijada de 1915, México, El Colegio de México, 1979.

VANDERWOOD, Paul

Disorder and Progress: Bandits, Police and Mexican Development, Lincoln, University of Nebraska Press, 1981.

Wasserman, Mark

Persistent Oligarchs. Elites and Politics in Chibuabua, Mexico, 1910-1940, Durham, Duke University Press, 1993.

Wilkie, James W.

The Mexican Revolution: Federal Expenditure and Social Change since 1910, Berkeley, University of California Press, 1967. 
Womack, John

"The Mexican Economy during the Revolution, 1910-20: Historiography and Analysis”, en Marxist Perspectives, 4 (invierno 1978), pp. 80-123. 